\title{
Complutum
}

ISSN: 1131-6993

\section{Los objetos de adorno en marfil del yacimiento del Cerro de la Virgen (Orce, Granada)}

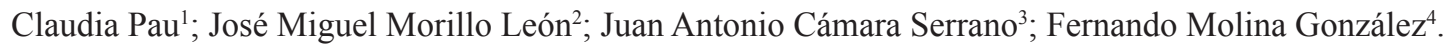

Recibido: 15 de junio de 2018 / Aceptado: 30 de noviembre de 2018

Resumen. En el presente trabajo se ha estudiado la totalidad (31) de los objetos en marfil recuperados en el Cerro de la Virgen (Orce, Gramada) durante las intervenciones arqueológicas realizadas entre 1963 y 1970. Se ha llevado a cabo el estudio morfo-tipológico, la caracterización de la materia prima y el análisis traceológico. Se han identificado 2 categorías diferentes de adornos (colgantes y botones), en algunos casos con subdivisiones. Se pueden sugerir diferencias temporales con el aumento de la variabilidad en momentos campaniformes (fase 2) y la presencia de algunas formas sólo en determinadas fases. Se han identificado principalmente las últimas fases de manufactura y procesos de reparación, y el análisis traceológico apoya la relación de los denominados "botones" con la vestimenta. En cuanto a la materia prima, el estudio óptico ha podido determinar el uso de marfil de elefante y de hipopótamo, además de elementos realizados sobre muestras de cetáceos y jabalíes. A través de FTIR se ha podido discriminar entre marfil de elefante asiático y africano. Frente a lo constatado en otros yacimientos, el uso de marfil de hipopótamo se constata desde el inicio de la ocupación en un momento precampaniforme y el marfil de elefante asiático sigue utilizándose hasta el Bronce Antiguo.

Palabras clave: Calcolítico; Edad del Bronce; colgantes; botones; materias primas; marfil.

\section{[en] Ivory ornament objects from the Cerro de la Virgen site (Orce, Granada)}

Abstract. The totality (31) of the ivory objects recovered in Cerro de la Virgen (Orce, Gramada) site during the archaeological interventions made between 1963 and 1970 have been studied here. Morpho-typological study, raw material characterization and the traceological analysis have been carried out. Two different categories of ornaments (pendants and buttons) have been identified, in some cases with subdivisions. Temporal differences can be suggested with the increase in variability in Beaker moments (phase 2) and the presence of some types only in certain phases. The last phases of manufacturing and repair processes have been identified, and traceological analysis supports the relationship of the so-called "buttons" with the clothing. As for the raw material, the optical study has been able to determine the use of elephant and hippopotamus ivory, in addition to elements made on cetaceans and wild boar samples. Through FTIR, it has been possible to distinguish between Asian and African elephant ivory. In contrast to what has been observed in other sites, hippopotamus ivory use can be seen from the beginning of the site occupation in a pre-Beaker moment and Asian elephant ivory continues to be used until Early Bronze Age.

Keywords: Chalcolithic; Bronze Age; pendants; buttons; raw materials; ivory

Sumario: 1. Introducción. 2. Material y método. 3. Resultados. 4. Discusión y conclusiones.

Cómo citar: Pau, C.; Morillo León, J. M.; Cámara Serrano, J. A.; Molina González, F. (2018): Los objetos de adorno en marfil del yacimiento del Cerro de la Virgen (Orce, Granada). Complutum, 29(2): 267-298.

\footnotetext{
Universidad de Granada. Departamento de Prehistoria e Arqueología, Facultad de Filosofía y Letras, Granada. claupau@ugr.es

2 University of Gothenburg. Department of Historical Studies. Göteborg. jmiguelmorillo@gmail.com

3 Universidad de Granada. Departamento de Prehistoria e Arqueología, Facultad de Filosofía y Letras, Granada. jacamara@ugr.es

4 Universidad de Granada. Departamento de Prehistoria e Arqueología, Facultad de Filosofía y Letras, Granada. molinag@ugr.es
} 


\section{Introducción}

El yacimiento arqueológico del Cerro de la Virgen se sitúa en un espolón amesetado entre el rio Orce, al norte, y dos barrancos a sus flancos occidental y oriental (Coordenadas UTM: 39.42320-2.35240) (Fig. 1). Este yacimiento ha sido considerado de gran interés arqueológico por su amplia secuencia estratigráfica, por sus importantes fortificaciones y por la presencia de una conducción de agua considerada una acequia de regadío (Schüle 1980, 1986).

El sitio fue descubierto por Pilar Acosta y Wilhelm Schüle en 1962 (Schüle 1980: 53). Posteriormente, el mismo W. Schüle dirigió varias campañas de excavación en los años 1963-64, 1965, 1967 y 1970 (Schüle y Pellicer 1966; Schüle 1980). Se documentaron viviendas, sepulturas, una muralla y una conducción de agua. En 1985 se llevó a cabo una campaña dedicada a la "limpieza, consolidación y cubrimiento" de tres cortes de excavación de la zona de la muralla (Sáez Pérez y Schüle 1987). Finalmente en 1986, el Departamento de Prehistoria y Arqueología de la Universidad de Granada realizó una nueva campaña de excavación que formaba parte del "Proyecto Millares", dirigido por los profesores Antonio Arribas y Fernando Molina, para obtener datos paleoambientales y estratigráficos.

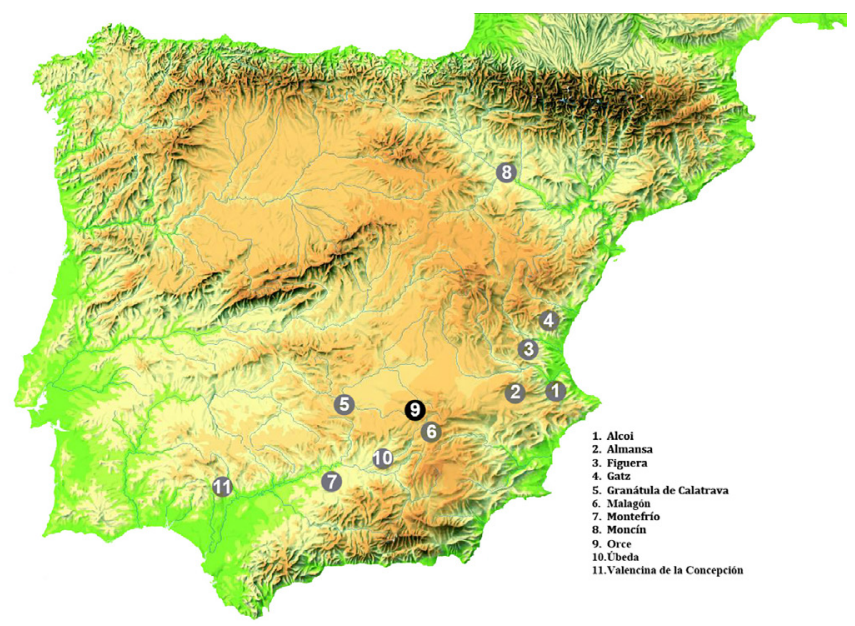

Fig. 1. Panorámica del yacimiento del Cerro de la Virgen, Orce, Granada.

Junto a dos memorias de excavación (Schüle y Pellicer 1966; Schüle 1980), numerosos trabajos se han dedicado al estudio de materiales procedentes de las excavaciones de W. Schüle (Boessneck 1969; Kalb 1969a, 1969b, 1973; Driesch 1972; Botella y Souich 1975; Botella 1976; Bubner 1977; Ulreich 1980, 1981. 1988, 1995; Uerpmann 1990; Hopf 1991a, 1991b; Carrillero 1992; Afonso 1993; Montero 1994; Mérida 1997; Rovira et al. 1997; Cet 2009; Schuhmacher 2011; Altamirano, 2013; Delgado 2013; Murillo 2013; Pau 2015, 2016).

En relación con la secuencia de ocupación del yacimiento (Kalb 1969b; Schüle 1980; Schüle y Pellicer 1966) se han distinguido 3 fases con subdivisiones internas: la Fase I, que correspondería a un horizonte precampaniforme, subdividida en IA y IB; la Fase II, horizonte Campaniforme subdividido en IIA, IIB y IIC; y, finalmente, la Fase III de la Edad del Bronce, subdividida en IIIA y IIIB. Seguirá un hiato hasta la construcción de una alquería en el periodo medieval andalusí. Un grupo de muestras procedentes de contextos de habitación excavados en 1986 fue datado por radiocarbono sumándose a tras obtenidas en las excavaciones de Schüle (Molina et al. 2004). Más tarde se publicaron nuevas dataciones procedentes de muestras de las tumbas excavadas por Schüle (Cámara y Molina 2009: 178, tab. II; Molina et al. 2014). Por último, nuevas dataciones de contextos de hábitat asociados a la muralla han sido también presentadas recientemente (Molina et al. 2017, p. 261). Con todos estos datos y con la ayuda de análisis estadísticos (suma de probabilidades y análisis bayesiano) se ha propuesto, en diferentes artículos, que la fase precampaniforme (Fase I) tuvo que ser muy breve y debió situarse inmediatamente antes del 2500-2450, el campaniforme (Fase II) se tuvo que manifestar entre el 2500-2450 y el 2150, mientras que un Bronce local, previo al Bronce Argárico de la región, empezaría en el 2150 hasta el 1900, cuando se iniciaría la influencia argárica (Molina et al. 2014; Molina et al. 2017) (Tabla 1). 


\begin{tabular}{|l|l|l|l|l|}
\hline FASES & Schüle & Periodo & & Cronología \\
\hline Fase I. & I & Pre Campaniforme & Campaniforme Inicial & $2500 / 2450-2350$ A.C \\
\hline Fase II1. & IIA & Campaniforme & Campaniforme Pleno & 2350 -2250 A.C. \\
\hline Fase II2. & IIB & & Campaniforme Final & $2250-2150$ A.C \\
\hline Fase II3. & IIC & & & $2150-1900$ A.C. \\
\hline Fase II4. & IIIA & Bronce Antiguo Local & & \\
\hline Fase III1. & & & & $1900-1750$ A.C. \\
\hline Fase III2. & & & & $1750-1550$ A.C. \\
\hline Fase III3. & IIIB & Bronce Argárico & & \\
\hline Fase III 4. & IIIC & & & \\
\hline
\end{tabular}

Tabla 1. Fases cronológicas y culturales del yacimiento del Cerro de la Virgen.

En lo que respecta a las cabañas, en época precampaniforme hay una serie de chozas realizadas con barro y ramaje (Kalb 1969b: fig. 3; Schüle 1980: 57) a las que suceden casas de planta circular en adobe (Kalb, 1969b: 217) $\mathrm{y}$, finalmente, en la Edad del Bronce, casas de tapial muy mal conocidas. Para Schüle ya desde el principio el poblado estuvo defendido por una muralla compleja que sufrió modificaciones a lo largo del tiempo (Schüle 1976), aspectos que se han confirmado recientemente (Molina et al. 2017). Además en 1998 fue realizada una prospección geofísica en la mitad norte del poblado que confirmó la existencia de otras líneas de muralla (Becker y Brandherm 2010: 271).

A partir de 1900 se constatan enterramientos bajo las viviendas y se han localizado tres tumbas en fosa de cronología anterior y sin ajuar (Molina et al. 2014). El material cerámico de la fase calcolítica responde claramente a los patrones formales y decorativos del Cobre Pleno y Reciente del Sudeste, siendo frecuentes las fuentes y los platos de borde biselado, apareciendo también recipientes de almacenaje ovoides con el cuello marcado (Schüle 1967, 1980). La decoración campaniforme muestra una clara evolución desde los estilos impresos hasta los incisos siendo frecuente en estos últimos la presencia de decoración también en el interior que desaparece al final de la Edad del Cobre. El análisis técnico ha demostrado que la mayoría de los recipientes son de manufactura local (Molina et al. 2017). Después de un Bronce Antiguo local, periodo previo al Bronce Argárico, donde aumentan las cerámicas carenadas y los recipientes de almacenaje, se documentan las influencias argáricas en formas carenadas, ollas y orzas (Bubner 1977: 1067).
En el yacimiento del Cerro de Virgen encontramos también artefactos en hueso, en particular punzones, y adornos en marfil (Ulreich 1988). En la industria lítica tallada hay artefactos realizados en sílex y cuarzo, destacando la producción de puntas de flecha sobre lasca por presión (Afonso 1993). Se ha destacado también la producción macrolítica en relación con actividades como la molturación del grano y también con instrumentos utilizados en otras actividades artesanales (Delgado 2013). Entre los elementos en metal (cobre, plata y oro) hay puñales, punzones, alfileres, anillos, brazaletes y aretes (Bubner 1977; Montero 1994; Rovira et al. 1997; Murillo 2013).

En cuanto al ambiente podemos señalar que desde el dominio del encinar en época calcolítica se pasó en el segundo milenio a un ambiente más degradado en el que la cobertura vegetal quedó reducida a la extensión del pino carrasco en las sierras (Rodriguez-Ariza y Esquivel 2005). En cuanto a las actividades agropecuarias, los aspectos más importantes son la drástica reducción en la importancia de los suidos durante el segundo milenio y el mantenimiento de la importancia del trigo durante este periodo (Buxó 1997: cuadro 6.4).

\section{Material y métodos}

Se ha estudiado la totalidad de los artefactos que se consideraron manufacturados en marfil (31 objetos de adorno: V-596, V-601, V-625, V-626, V-627, V-635, V-638, V-639a, V-639b, V-750, V-752, V-758, V-773, V-778, V-784, V-943, V-968, V-974, V-985, V-1063, V-1126, V-1287, V-1440, V-1451, V-1452, V-1502, 
$\mathrm{V}-1585, \mathrm{~V}-2212, \mathrm{~V}-2941, \mathrm{~V}-3391$ y V-S/N) que fueron recuperados en el yacimiento del Cerro de la Virgen, en contextos domésticos de la zona suroeste del yacimiento, durante las antiguas intervenciones arqueológicas (19631970). Las piezas fueron descritas inicialmente por W. Schüle (Schüle y Pellicer 1966; Schüle 1980) y más tarde por V. Mérida (1997), que enfocó su análisis sobre la tecnología de los botones, y finalmente han sido incluidos por $\mathrm{C}$. Pau en su tesis doctoral (Pau 2016).

En este trabajo se presentará el estudio morfológico y morfométrico de los objetos de adorno, lo que nos permitirá proponer una clasificación tipológica completa. Todos los artefactos han sido dibujados, fotografiados y escaneados. Las imágenes han sido recogidas en láminas a escala 1:1 y con un calibre digital se han registrado las medidas en una base de datos. A continuación se ha realizado un análisis traceológico para determinar las técnicas de fabricación y el uso de los objetos de adorno, examinando los artefactos con la lupa binocular y el microscopio electrónico de barrido (SEM).

En lo que respecta al análisis de los elementos en marfil, nos interesa principalmente la identificación concreta de la materia prima y si es posible su procedencia. Todos los objetos incluidos en el análisis técnico y tipológico han sido analizados con este fin. En primer lugar hay que señalar que aunque el término marfil incluye materiales de muy diversa procedencia, como los de foca (Javaloyas 2006), jabalí (Sus scrofa) y cachalote (Physester macrocefallus), considerados materia prima de circunstancia (Schuhmacher et al. 2013), son los elementos de proboscideos (elefantes) y artiodactylos (hipopótamos) los que deben ser considerados como verdadero marfil. En el primer caso, aparte del marfil fósil (Palaeoloxodon antiquus, Mammuthus primigenius), disponible en ciertas zonas de Europa, se utilizaron colmillos de elefante asiático y africano (principalmente de sabana).

Para el estudio de la materia prima, en primer lugar se ha realizado un análisis óptico basado en la metodología establecida por Espinza y Mann (1992). Ésta consiste en el estudio de los patrones de las lamellae que conforman el marfil, primeramente diferenciando las piezas en las que las líneas de Schereger, propias de los proboscídeos, están presentes de las que muestran otros patrones, es decir, lamellae onduladas en el caso del hipopótamo, extremadamente delgadas y concéntricas para los cetáceos, y total ausencia de patrón para el jabalí (Espinoza y Mann 1992; Locke 2008). Merece la pena mencionar que en este estudio, si bien hemos utilizado la presencia de líneas de Schreger para identificar marfil de proboscídeo, hemos ignorado deliberadamente el intento de diferenciar las diversas especies de éstos en base a aquellas, ya que mientras algunos expertos consideran esta diferenciación inviable (Espinoza y Mann 1993; Palombo y Villa 2001), otros autores defienden que es posible basándose en la organización tridimensional de los túbulos de dentina (Trapani y Fisher 2003). Sin embargo, teniendo en cuenta la organización de los túbulos en tres dimensiones, otros autores defienden que ni aun así es posible diferenciar los diferentes proboscídeos mediante esta metodología ya que la variabilidad es muy alta, no solo entre las diferentes especies, sino incluso en las diferentes secciones del colmillo (Virág 2012; Albéric et al. 2017); además, para estos estudios se requiere bien la preparación de la muestra para mostrar diversos ángulos de la organización de los túbulos de dentina, bien el uso de técnicas como la tomografía, que no hemos utilizado en esta ocasión.

Seguidamente, el marfil de elefante fue seleccionado para su estudio mediante Espectroscopía de infrarrojo por transformación de Fourier (FITR, según sus siglas en inglés), siguiendo la metodología propuesta por A. Banerjee (Banerjee et al. 2008; Schuhmacher y Banerjee 2012, Banerjee y Huth 2012). El instrumento usado ha sido JASCO 6200, con software SPECTRA MANAGER v2, propiedad del Centro de Instrumentación Científica (CIC) de la Universidad de Granada. Los tiempos de exposición al haz de infrarrojos variaron en función de las características propias de cada pieza. Finalmente, para confirmar los resultados, se realizó un estudio estadístico mediante Análisis de Componentes Principales (PCA por sus siglas en inglés).

En el caso del hipopótamo, no se puede determinar la procedencia concreta ya que en ambas áreas susceptibles de ser el origen de la materia prima (africana y asiática), el hipopótamo corresponde a la misma especie. Únicamente estudios isotópicos (Lafrenz 2004) que no se han realizado en este estudio, también por su carácter destructivo (aunque sea de una mínima parte de la muestra), podrían contribuir a esclarecer con certeza la fuente de abastecimiento utilizada, contrastando los datos con 
estudios sobre las similitudes en los objetos acabados (si es que fueron éstos los que circularon y no la materia prima en bruto), aspectos fundamentales para futuros estudios sobre los contactos entre las diferentes comunidades de la Prehistoria Reciente.

\section{Resultados}

\subsection{Estudio tipológico. Clasificación}

Los 31 artefactos estudiados se han agrupado en 2 categorías tipológicas (colgantes y botones), siguiendo clasificaciones previas (Barge 1982; Uscatescu 1992; Bonnardin 2009; Pascual 1998; Barciela 2008; López 2011; Altamirano 2013; Altamirano 2014; Pau 2016). Además las categorías incluyen subdivisiones; en la primera se han distinguido 2 grupos morfológicos mientras que en la categoría II se han separado 7 grupos. El grupo 3 de la categoría II se ha dividido ulteriormente en 2 subgrupos y el grupo 7 en 3 subgrupos.

\section{Colgantes (categoría I)}

Se han definido como colgantes los artefactos con una longitud mayor respecto a su anchura y con perforación en una de las extremidades.

Se ha considerado como colgante de forma trapezoidal (grupo 1) (Fig. 2) el artefacto V-2212 (Schüle 1980: lámina 1), que presenta las caras trapezoidales y sección rectangular, y un pedúnculo con las caras rectangulares y perforación central circular con sección cilíndrica. El colgante está roto en la base. Es posible que este adorno sea un fragmento de un ídolo en dos piezas análogo al del Malagón (Arribas 1977; Altamirano 2013). Hemos clasificado como colgante pentagonal (grupo 2) (Fig. 2) un adorno que presenta cinco lados irregulares. Es el artefacto V-758 (Schüle 1980: lámina 98), que muestra un cuerpo muy aplanado y en el vértice del triángulo un agujero de forma circular y sección cilíndrica.

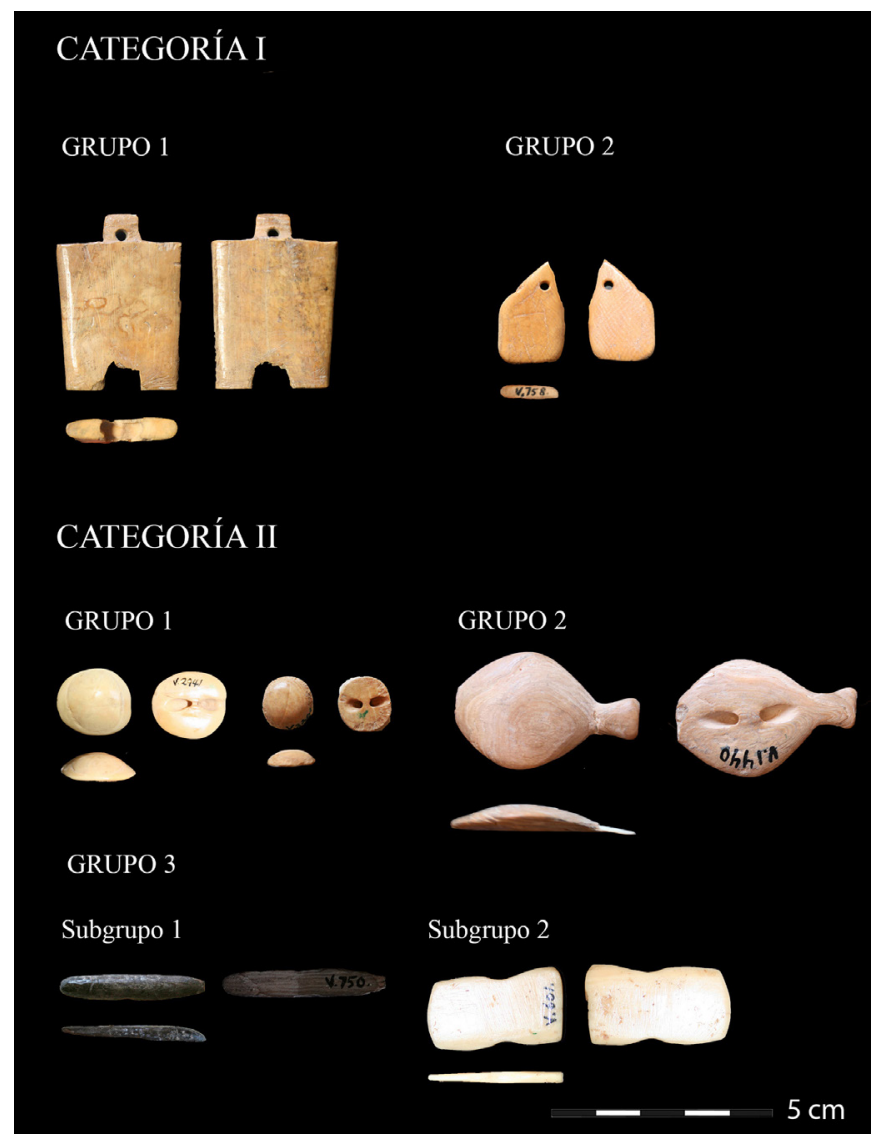

Fig. 2. Colgantes (Categoría I): Colgante trapezoidal (grupo 1)(V.2.212), colgante irregular (grupo 2)(V.758); Botones (Categoría II): botones a casquete de esfera (grupo 1) (V. 2.941 y V. 3.391), botón con alita lateral (grupo 2)(V. 1.440), botones con doble extremidades (grupo 3) (V. 750 y V. 601). 


\section{Botones (categoría II)}

Se reúnen bajo la denominación de botones objetos a los que, por sus parecidos formales con los botones modernos, se les atribuye la misma función. Presentan una variada morfología y varios métodos de sujeción.

Los botones de casquete esférico (grupo 1) son pequeños elementos que presentan sección plano-convexa, la cara ventral plana (circular o elíptica) y la dorsal curvilínea. La perforación se sitúa en la cara ventral, dos agujeros que se encuentran en forma de "V". Consideramos que estos elementos constituyen un grupo independiente dentro de la categoría de los botones, diferenciándose de los demás derivados de la esfera por su sección plano-convexa (mientras que los botones hemisféricos tienen sección semicircular, y los esféricos circular). Muchos autores no diferencian este grupo de botones de los hemisféricos, mientras que J. Arnal $(1954 ; 1973)$ habla de "botones pirenaicos" y "botones de bóveda baja", los primeros perfectamente hemisféricos y con un diámetro comprendido entre los 0,7 y los $0,8 \mathrm{~cm}$, y los segundos de mayor tamaño. A. Uscatescu (1992) habla de botones derivados de la esfera diferenciando entre botones esféricos, de casquete de esfera, hemisféricos, de segmento de esfera y añadiendo en el mismo grupo, a diferencia de nuestra propuesta, las variedades con apéndices laterales. De esta morfología se han identificado, en el conjunto de objetos estudiados, dos artefactos (V-2941 y V-3391) con dos agujeros de forma oval. Además la pieza V-2941 (Schüle 1980) presenta un motivo circular inciso en el dorso (Fig. 2).

Los botones con "alitas laterales" (grupo 2) son artefactos que presentan un cuerpo central con perforación en "V" y dos alitas laterales, que pueden estar apenas esbozadas o bien delineadas. Pertenece a este grupo un único botón (V-1440) (Schüle 1980: lámina 45) (Fig. 2) que presenta cuerpo central de forma romboidal con sección plano-convexa y conserva una de las dos alitas laterales de forma trapezoidal. Este grupo de adornos fueron definidos en Italia con la terminología de alamaros (Taramelli 1909) o de pendagli ad alamaro (Cornaggia Castiglioni y Calegari 1980). V. G. Childe (1949) denominó estos adornos como en bobbin shapes, mientras que P. Héléna, ya en 1937, crea el término de boutons de tortue, refiriéndose a aquellos de estos adornos que presentan una forma parecida a la de este animal (Héléna 1937). Por el contrario, J. Roche y O. Da Veiga Ferreira, en 1961, consideraron algunos de estos adornos como "antropomorfos estilizados" (Roche y Da Veiga Ferreira 1961). Con el paso del tiempo, muchos investigadores utilizaron la terminología de botones en alamaro y abusivamente la de botones en tortue, o en "antropomorfo", para indicar todos los botones con alitas sin diferenciaciones. Todas estas denominaciones son excesivamente genéricas como ya había dicho C. Hebras (1965) en relación con el mal uso del término de botones en "tortue". Recientemente los investigadores portugueses distinguen entre botões de tartaruga, indicando los elementos con apéndices más reducidos, y botões en forma de laço o papillon, especificando papillon, que se usa em alternativa à gravata, o, en forma de "carrinho

Los botones con dobles extremidades (grupo 3) son pequeños elementos que pueden presentar sección plano convexa (subgrupo 1) o morfología plana, como una plaqueta (subgrupo 2). Hemos colocado estos elementos en la categoría de los botones, sin excluir la posibilidad de poder haber tenido otro uso. Además el artefacto del subgrupo 1 (V-750) (Schüle 1980: 34, tabla 6), con cuerpo oval y huellas de alteración térmica, al tener una doble extremidad puntiaguda se puede denominar también como "doble hacha". La morfología del artefacto del subgrupo 2 (V-601) (Schüle 1980: lámina 96), con las caras pseudorectangulares y un estrechamiento en la parte central (Fig. 2), recuerda la de los ídolos y podría ser un pequeño ídolo-colgante.

Se han definido como cónicos los botones (grupo 4) con perforación en "V" que presentan la base plana de forma circular u oval, la cara dorsal de forma cónica y la sección de forma triangular. En el yacimiento de Cerro de la Virgen se han encontrado dos botones cónicos: V-1451 (Schüle 1980: lámina 76) y V-1287 (Schüle 1980: lámina 45) (Fig. 3). Del primer elemento se conserva sólo la mitad longitudinal, con un agujero oval en la base que, como se puede ver observando la parte fracturada, se unía con una perforación en "V" a otro agujero. El segundo botón presenta una forma cónico-piramidal, la base rectangular pero con las esquinas redondeadas y dos agujeros ovales unidos en "V", aunque en la base la zona que separa las dos perforaciones está rota. 


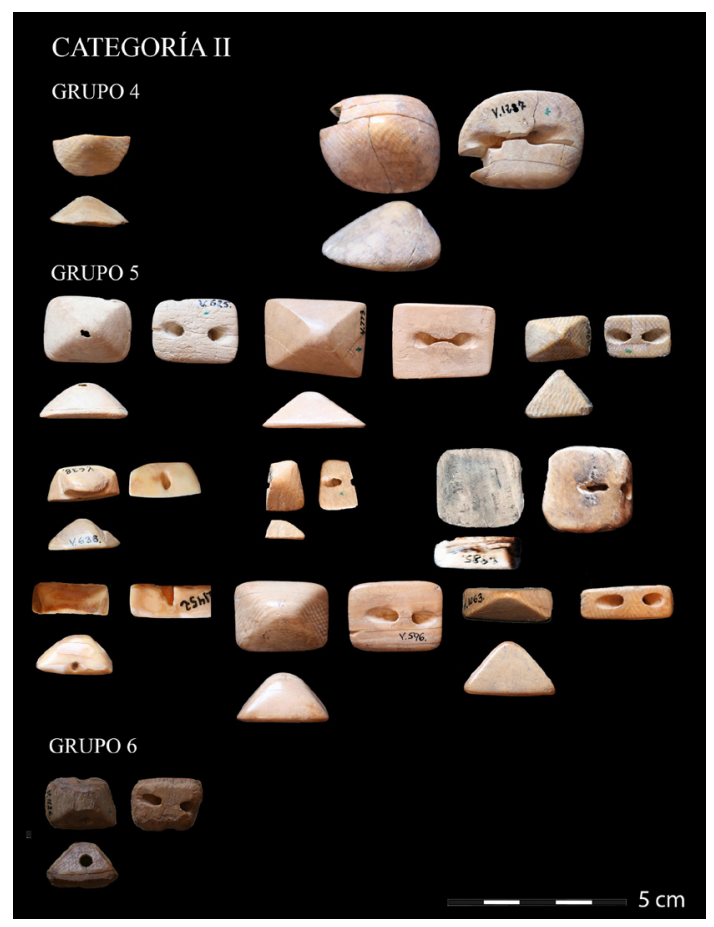

Fig. 3. Botones (Categoría II): botones cónicos (grupo 4) (V. 1.451, V. 1.287), botones piramidales (grupo 5) (V. 625, V.773, V.968, V. 638, V. 784, V. 985, V. 1.452, V. 596, V. 1.063); botón tronco-piramidal (grupo 6) (V. 1.126).

Los botones que definimos como "piramidales" (grupo 5) son elementos que presentan una base plana de forma cuadrada o rectangular, la parte dorsal formada por 4 superficies planas triangulares convergentes (Pascual 1998: 167) y sección triangular. En el conjunto de material estudiado hay 9 botones de forma piramidal (Fig. 3): V-625 (Schüle 1980: lámina 98), V-773 (Schüle 1980: lámina 98), V-968 (Schüle 1980 lámina 90),V-638 (Schüle 1980: lámina 998), V-784 (Schüle 1980: lámina 94), V-985 (Schüle 1980: lámina 90), V-1452 (Schüle 1980: lámina 51), V-596 (Schüle 1980: lámina 103), y V-1063 (Schüle, 1980: lámina 41), 7 con base rectangular, uno (V-985) con base cuadrangular y otro (V-773) pseudorectangular, todos con las esquinas redondeadas y perforación en "V", con los dos orificios de forma oval. El botón V-625 presenta una rotura en el vértice donde se une la perforación. En la base del artefacto V-773 la zona entre los dos agujeros está rota. Están rotos los botones V-638, V-784, V-1452 y del botón V-638 se conserva sólo la mitad del artefacto con uno de los dos orificios de perforación. Además la particularidad de este adorno es la presencia de una incisión marcada alrededor del vértice. También del botón V-784 queda sólo la mitad con un agujero. Del botón V-1452 se conserva la mitad y presenta en la que tenía que ser la base los restos de la perforación en "V", mientras en el lateral, cerca del borde de la base, presenta un nuevo orificio circular pasante (sección cilíndrica). Es probable que la pieza V-985-sea lo que queda de un botón piramidal cuyos agujeros, que se unen en "V", están ubicados uno en la base y descentrado y otro en la parte baja del lateral.

Los botones tronco-piramidales (grupo 6) son los adornos que presentan la forma de un tronco de pirámide. Pertenece a este grupo un único ejemplar, el botón V-1126 (Schüle 1980: lámina 90) (Fig. 3), que está roto en un lado. Es una pieza muy interesante porque presenta dos pares de agujeros de perforación. El primer par está formado por dos orificios ovales en la base que se unen en "V", mientras que el segundo por dos agujeros circulares ubicados en el centro de las caras laterales unidos en línea recta. Las dos perforaciones convergen en el interior del botón.

Los 11 artefactos que se han recogido como botones prismáticos (grupo 7) (Fig. 4), V-627 (Schüle 1980: lámina 98), V-635 (Schüle 1980: lámina 98), V-778 (Schüle 1980: lámina 98), V-974 (Schüle 1980: lámina 90), V-1585 
(Schüle, 1980: lámina 41), V-943 (Schüle 1980: lámina 90), V-1502 (Schüle 1980: lámina 51), V-752 (Schüle 1980: 34, tabla 6), V-626 (Schüle 1980: lámina 98), V-639-a (Schüle 1980: lámina 98) y V-639-b, son elementos que tienen la forma de un prisma y pueden presentar diferentes secciones laterales (Uscatescu 1992: 38). Podemos diferenciar 3 subgrupos dependiendo de la forma de las caras más pequeñas: triangulares (8), trapezoidales (2) y rectangulares (2).

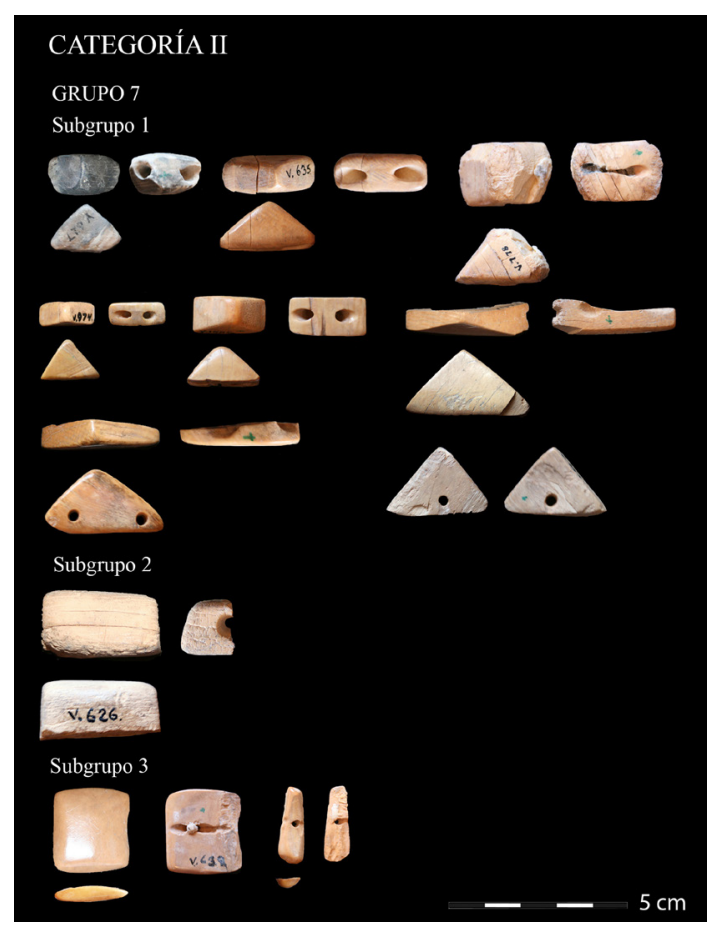

Fig. 4. Botones (Categoría II): Botones prismáticos (grupo 7) (V. 627, V. 635, V. 778, V. 974, V. 1.585 , V. 943 , V. 1.502, V. 750, V. 626,V. 639-1, V. 639-2).

En el subgrupo 1 (V-627, V-635, V-778, V-974, V-1585, V-943, V-1502, V-752) los botones prismáticos triangulares son elementos que tienen la cara ventral de forma rectangular, la dorsal formada por dos planos rectangulares y dos triangulares que convergen. Presentan la perforación en "V" (Uscatescu 1992: 38; Pascual 1998: 167). A. Uscatescu relaciona estos botones con los semicilíndricos, porque considera que la diferencia entre los dos dependería de un mayor o menor trabajo del soporte (Uscatescu 1992: 74). Los botones V-627 y V-778 presentan una morfología irregular. El primero, con traza de alteración térmica, está roto en la base, y el segundo en uno de los lados y en el vértice. El botón V-635 está dividido en tres partes y el botón V-778 presenta una rotura en el espacio entre los dos agujeros de perforación. De los adornos V-943 y V-1502 quedan sólo fragmentos. Del primero queda sólo un lateral y una parte reducida de la base que conserva parte de un orificio de perforación. En el segundo queda sólo una pequeña porción de la base y de la extremidad y una de las caras laterales triangulares. Esta pieza muestra una particularidad, ya que dispone de dos pares visibles de agujeros para su uso. En la base, de hecho, se puede ver, aunque incompletos, dos agujeros ovales y su unión en "V". Cuando el botón se fracturó se realizaron dos nuevos orificios, de forma circular con sección cilíndrica, en las caras laterales triangulares en proximidad de la base. Es probable que el artefacto V-752 sea lo que queda de un botón prismático que presenta una única perforación de forma circular y sección cilíndrica.

En el subgrupo 2 se puede incluir el adorno $\mathrm{V}-626$. Este botón es un prisma con la parte dorsal formada por cinco caras, tres de ellas rectangulares y las dos extremidades trapezoidales, aunque presenta los vértices del trapecio suaves lo que genera caras sin aristas casi como si fuera la sección de un cilindro. Por otra parte el tramo de perforación conservado es longitudinal y presenta sección cilíndrica. 
En el subgrupo 3 se integran dos botones: V-639-a, y V-639-b. El primero presenta la forma de un prisma cuadrangular pero muy aplanado y está roto en una extremidad. En la base se sitúa la perforación en "V" que está rota en la unión de los dos orificios. El segundo objeto creemos que originalmente sería similar al anterior, aunque actualmente presenta una forma irregular. Fue reutilizado y la perforación es de sección cilíndrica.

\section{Fragmentos}

Tenemos que añadir a los colgantes y botones estudiados el hallazgo de algunos fragmentos de marfil (V-S/N) posiblemente pertenecientes a objetos de adorno personal, no incluidos por su estado de conservación en ninguno de los grupos anteriores.

\subsection{Huellas de manufactura}

El análisis de las técnicas de fabricación de los objetos de adorno del Cerro de la Virgen ha dado buenos resultados salvo en el caso de elementos muy deteriorados (V-1287, V-1126, V-985, V-627, V-778, V-626) o cuando las huellas de uso han borrado las técnicas (V-968, V-638, V-784, V-1063, V-635, V-974, $\mathrm{V}-1585$ y V-1440). En la mayoría de los artefactos se han identificado las últimas fases de elaboración. De hecho, las superficies presentan un pulido uniforme pero en algunos casos se han identificado zonas todavía no refinadas (V-2212, V-758, V-3391); en otros se han reconocido estrías de gran tamaño seguramente obtenidas con un elemento abrasivo más grueso o huellas de talla sin pulido posterior (V-1126, V-773).

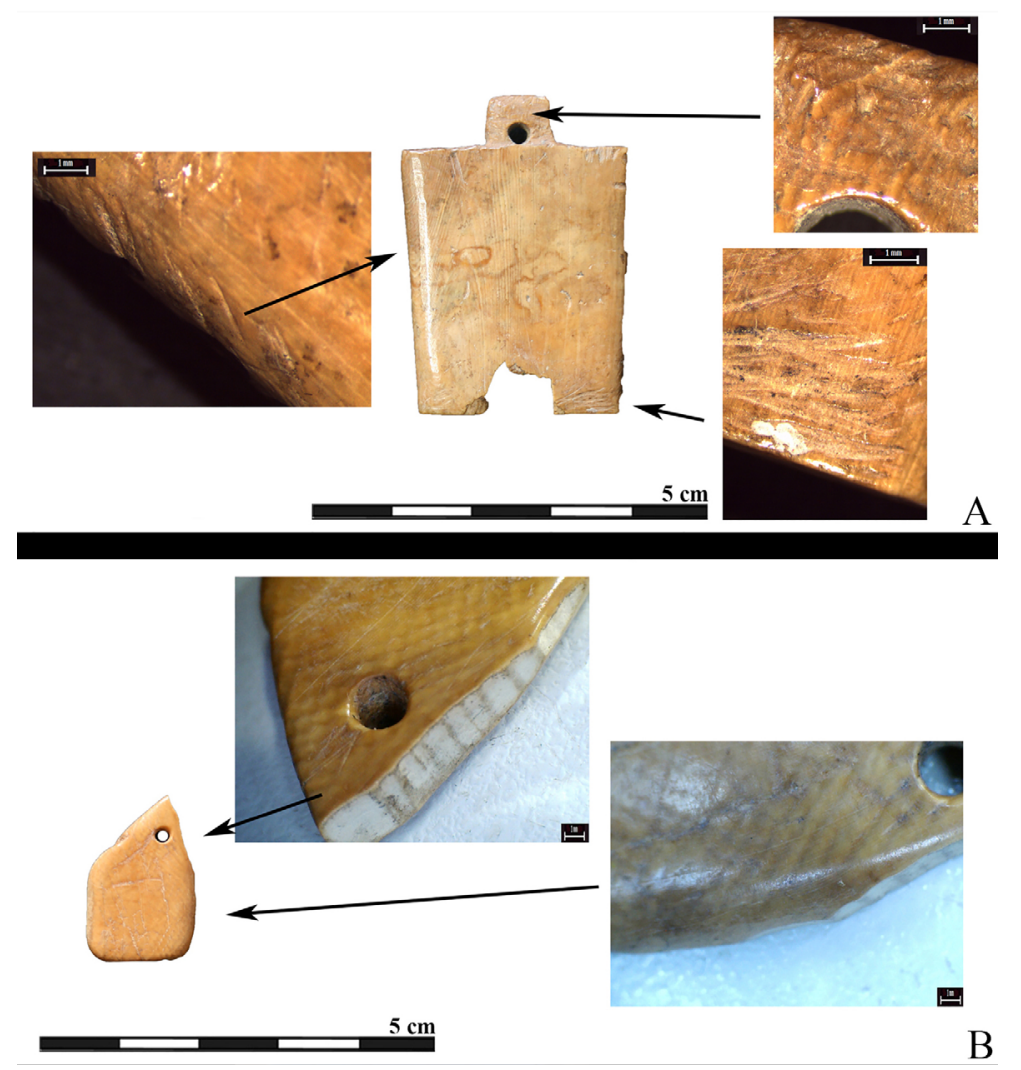

Fig. 5. A. En el colgante trapezoidal con pedúnculo V-2212 el refinado no es total hay huellas muy marcadas de corte y estrías muy profundas y gruesas de abrasión; B. En el colgante V-758 en el borde de la base del botón así como en el margen superior del colgante encontramos la superficie recortada y no refinada.

En el colgante trapezoidal con pedúnculo V-2212 hay huellas de pulido en la superficie y en los bordes del objeto, aunque el refinado no es total. De hecho, en el pedúnculo con agujero de sujeción hay huellas muy marcadas de corte y estrías muy profundas y gruesas de abrasión (Fig. 5A). También en el colgante V-758 (Fig. $5 \mathrm{~B})$, como en el botón a casquete de esfera 
V-3391, buena parte del objeto presenta la superficie pulimentada conseguida con la técnica de la abrasión muy fina y un pulido posterior. Sin embargo, en el borde de la base del botón así como en el margen superior del colgante encontramos la superficie recortada y no refinada. El botón V-1126 presenta huellas de cortes y estrías de abrasión y en el botón V-773 se identifican profundas huellas de abrasión.

La técnica utilizada para horadar los botones, perforación con taladro, se ha podido identificar sobre todo observando los artefactos rotos, como el V-1451 (Fig. 6), donde queda visible la sección de la perforación. En el artefacto V-943 (Fig. 7) parece que se reali-

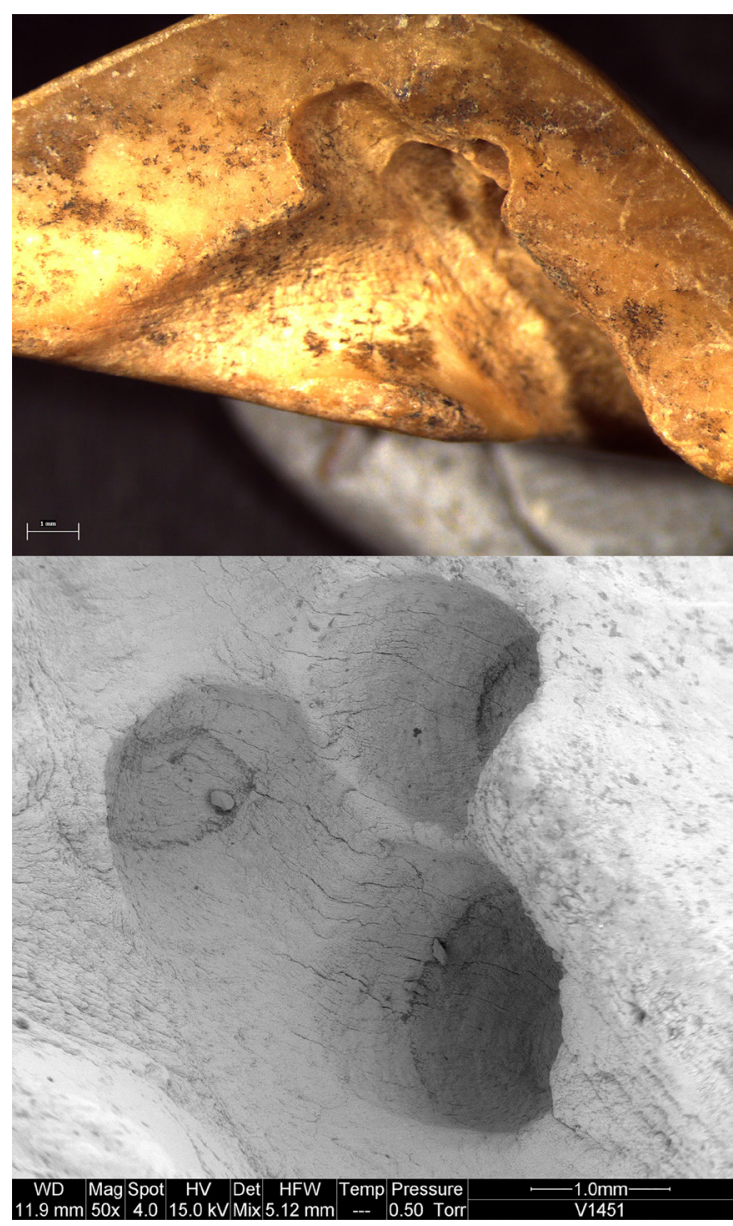

Fig. 6. Perforación con taladro en el botón V-1451. zaría una primera perforación perpendicular al plano basal de la pieza con el fin de conseguir un punto de apoyo en el que situar el taladro y obtener más fácilmente la perforación oblicua que se realizaría posteriormente. Esto confirma lo que había sido ya sugerido, en algunos casos, por otros investigadores (López 2011: 467). En otros botones con perforación en "V", V-1452, V-943 y V-1502 y cilíndrica V-626, es perfectamente visible el recorrido del taladro de punta metálica fina. Además, el taladro se utilizó también para la perforación de los dos colgantes como testimonia la presencia de estrías concéntricas en los bordes internos de los orificios.
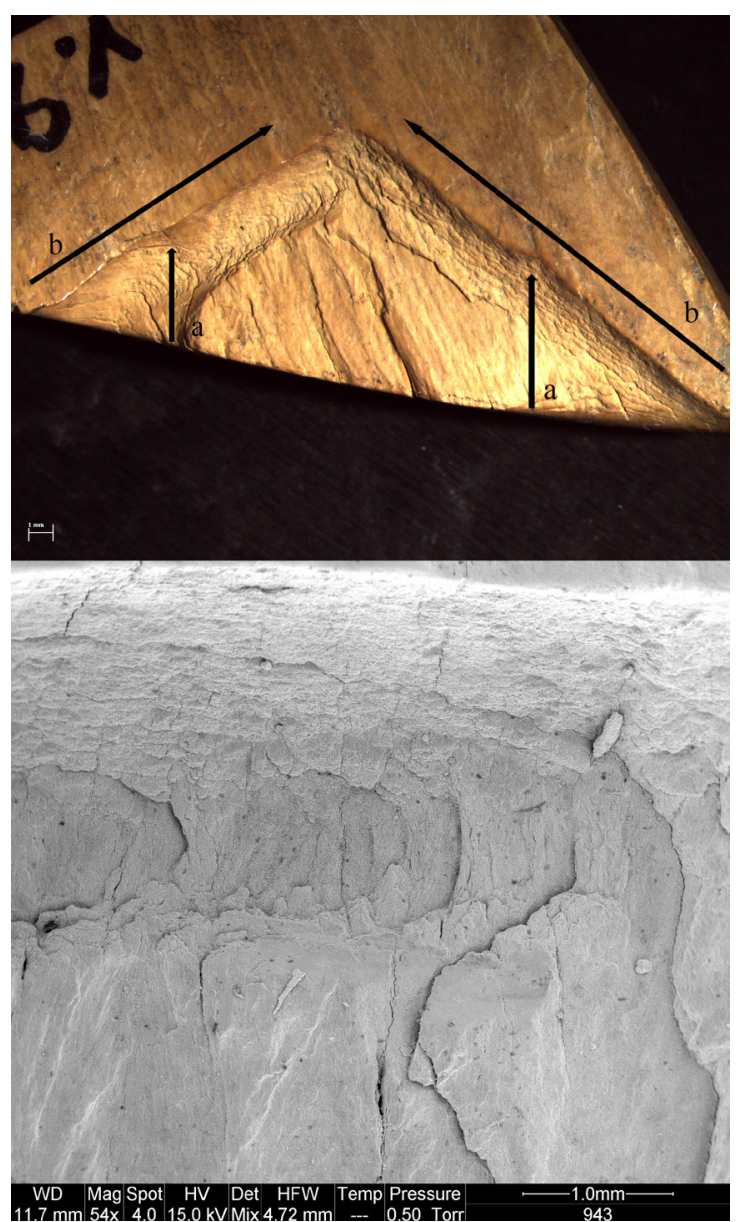

Fig. 7. Trayectoria de la perforación en el botón V-943. 


\subsection{Uso}

En los artefactos estudiados se han identificado huellas de uso más o menos evidentes (muescas, estrías, manchas de pulido, etc.). Además, observando la localización del desgaste y realizando pruebas experimentales, ha sido posible reconstruir la forma de llevar algunos de estos adornos personales.

El colgante V-758 del grupo 2 habría podido ser un fragmento de un colgante más grande roto por el uso y reutilizado. Esto explicaría por qué uno de sus márgenes no ha sido pulido después de la talla. Este objeto presenta una muesca de uso en uno de los bordes de los lados superiores y varias estrías bien marcadas en la cara anterior y más tenues en la posterior, bien visibles incluso macroscópicamente (Fig. 8). Observando estas huellas podemos sugerir que el adorno se colgaría utilizando una cuerda o hilo muy fino, que se enrollaría en el agujero y en el cuerpo de la pieza. También se ha notado un gran desgaste de la superficie de la base que testimoniaría un uso continuo del adorno.
El botón a casquete esférico V-2941 (Fig. 9) presenta un surco en el dorso paralelo al borde del objeto en todo su perímetro. En la base, la parte comprendida entre los dos orificios aparece desgastada y muestra una musca en una de las perforaciones que coincide con la parte más profunda del surco antes referido. Nuestro estudio revela el posible uso de este objeto como colgante, más que como botón, posiblemente como único elemento de un collar, como indicaría el desgaste uniforme de sus márgenes, seguramente determinado por la fricción con la piel o las vestimentas y no por el roce con otros elementos de un collar. El surco del dorso, por la irregularidad del trazo y por su profundidad, no se ha interpretado como un motivo decorativo en sí, pero parece estar en relación con una cinta de revestimiento probablemente metálica. Posiblemente el hilo pasante por la perforación en "V" quedaba fijado también en la parte dorsal a la altura de la muesca, cubierto en parte por el revestimiento y quedando así el colgante más fijo.

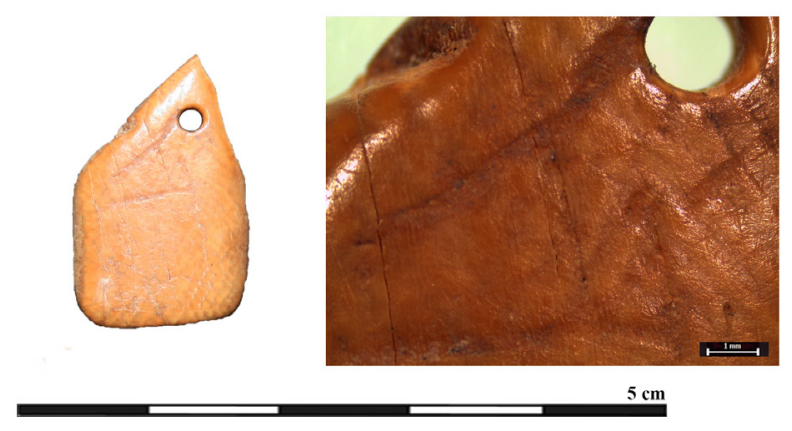

Fig. 8. Huellas de uso en el botón V-758.

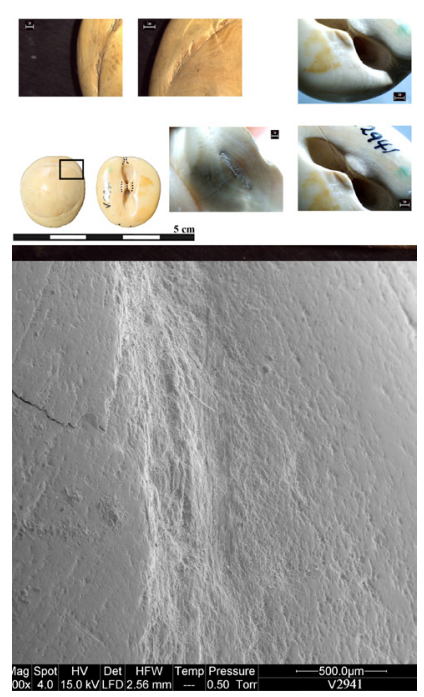

Fig. 9. Surco en el dorso paralelo al borde del botón a casquete esférico V-2941. 
El botón V-625, aunque presente la superficie en mal estado de conservación, muestra todavía huellas de uso visibles, en particular una pequeña muesca entre el orifico y el borde que tiene correspondencia con las estrías de uso identificadas en la superficie del botón entre los dos agujeros de perforación. Todo ello nos sugiere su uso como colgante. En el botón V-968, en el punto de unión de los orificios, hay muescas y estrías producidas por los hilos con los cuales había sido cosido, mientras que las manchas de pulido en el cuerpo nos indican los roces con las vestimentas. En el pequeño botón V-627 se puede observar la presencia de dos pequeñas muescas en uno de los orificios y otra en el otro, y estrías muy finas entre los dos agujeros, aunque no claras teniendo en cuenta la superficie quemada del elemento. En el botón con doble extremidad V-750 (Fig. 10) se han podido identificar dos pequeñas muescas en la parte central de los lados largos, seguramente provocadas por un hilo sutil enrollado en ese punto. Estrías por el roce de cuerdas o hilos están presentes también en los bordes centrales del botón V-601. Los botones V-635, V-974, V-1063 y V-1585 presentan huellas de uso en el punto de unión de los dos agujeros, dos estrías paralelas y los bordes desgastados. Las trazas de uso del botón con "alitas laterales" V-1440 (Fig. 11) son muy peculiares; observándolas se puede ver perfectamente la trayectoria del hilo con el cual el objeto había sido fijado. Todos estos elementos se pueden considerar verdaderos botones.

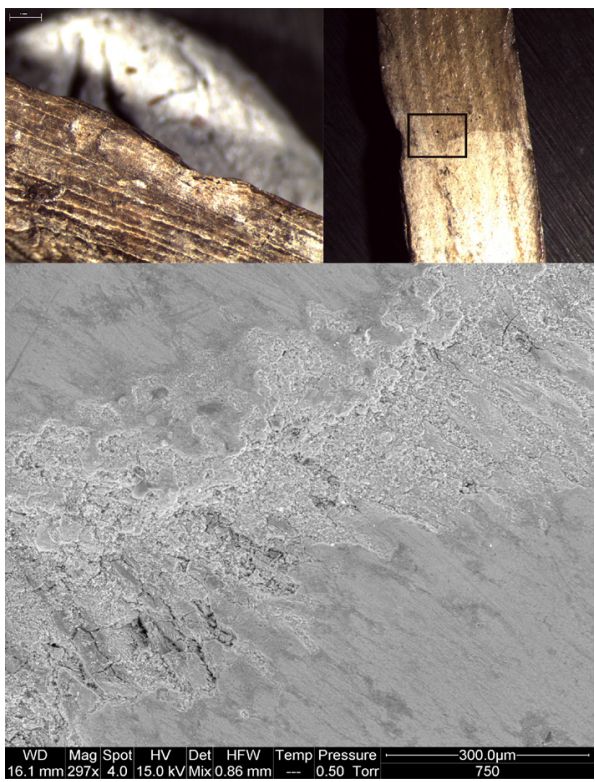

Fig. 10. Muescas en la parte central de los lados largos en el botón con doble extremidad V-750.

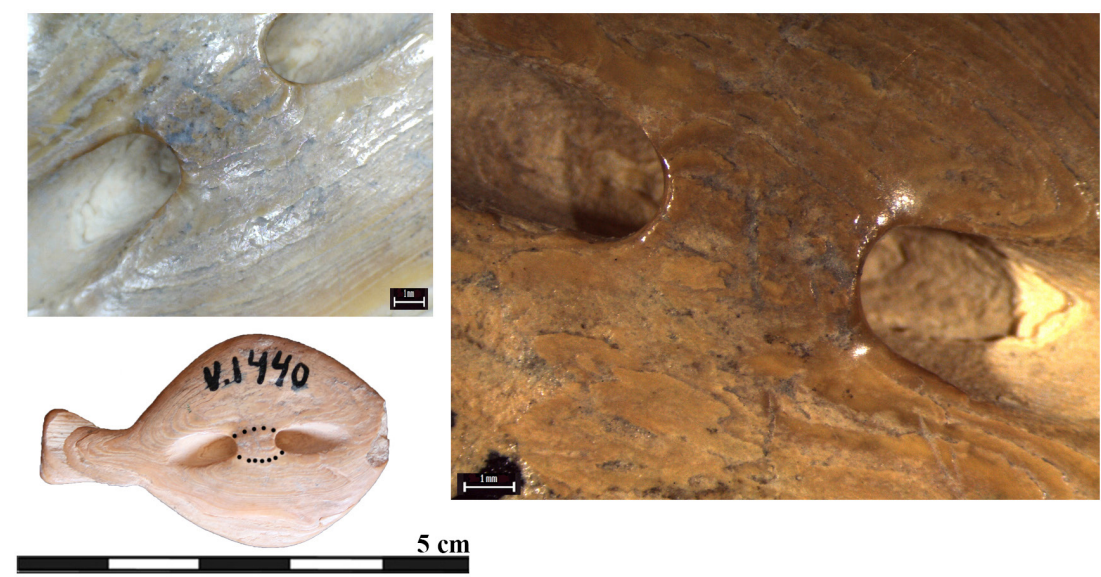

Fig. 11. Huellas de uso en el botón con “alitas laterales" V-1440 
En los botones el uso prolongado en el tiempo está demostrado por la rotura en la base de la parte de unión de los dos agujeros de perforación, que se puede anotar en 4 artefactos (V-1287, V-778, V-639-a y V-773) (Fig. 12). Podemos añadir que algunos presentaban un desgaste muy marcado de la superficie de las caras y bordes. Es el caso de los botones, V-1452, V-974, V-1585, V-1063, V-638, V-784, V-639-b, V-639-a. No se han encontrado huellas de uso en el botón piramidal V-1126 que presenta 2 pares de perforaciones funcionales; por lo tanto no sabemos si fueron utilizadas las dos contemporáneamente o no. En el objeto V-601 se pueden observar manchas de brillo en las extremidades de las dos caras, aunque no está claro si se trata de huellas de uso o del pulido de la superficie; desconocemos si el objeto había sido utilizado como colgante o como botón o de algún otro modo, aunque se pueden reconocer estrías en los bordes centrales como si hubiera estado atado con un hilo o una cuerda muy fina.

La importancia que tenían los botones para quien los llevaba y el significado simbólico que podían contener está demostrado por la presencia de artefactos que se rompieron y fueron reutilizados como colgantes, aunque lo que quedaba era una porción pequeña o amorfa del objeto original. Uno de los casos más claros es el botón V-638 (Fig. 13), en el que no se utilizó el único agujero conservado (en el cual se pueden notar manchas de pulido de su primer uso), sino que se llevó colgado a través de una pequeña cuerda enrollada en una pequeña ranura perimetral cercana al ápice del dorso.

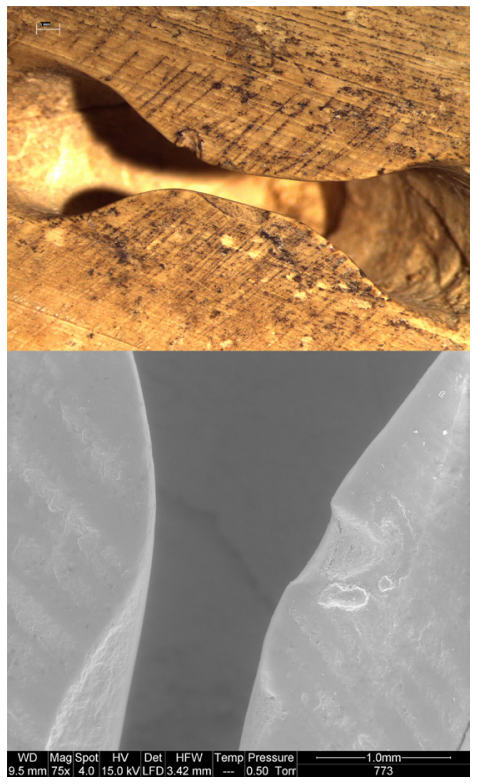

Fig. 12. Rotura en la base de la parte de unión de los dos agujeros de perforación en el botón V-773).
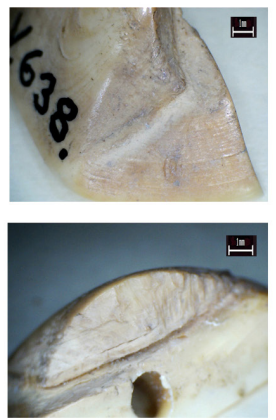
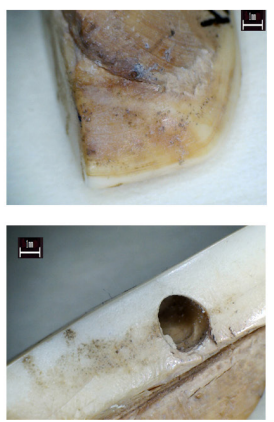
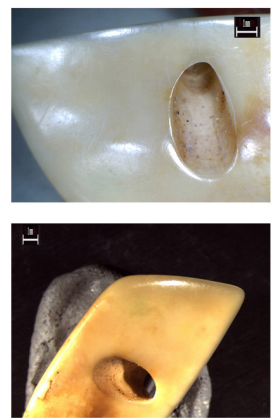

$5 \mathrm{~cm}$

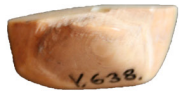

Fig. 13. Huellas de uso en el botón V-638. 


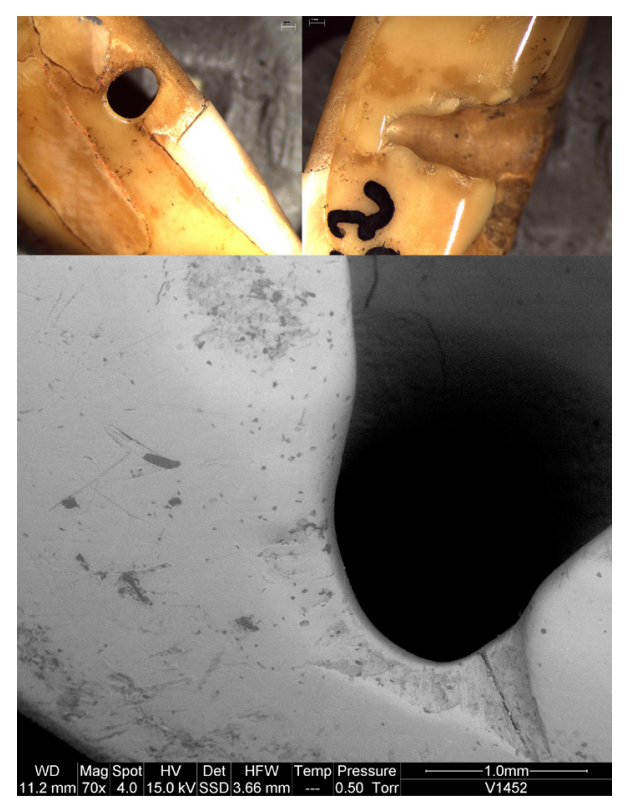

Fig. 14. Huellas de uso en el botón V-1452.

El botón prismático $\mathrm{V}-1502$ se rompió y fue reutilizado gracias a una nueva perforación de sección cilíndrica, mientras que el botón V-752 se reutilizó a partir de un único agujero central. También el botón piramidal V-1452 (Fig. 14), roto de antiguo, fue reutilizado. En el fragmento que se conserva se puede ver todavía la sección de la anterior perforación en "V" mientras el artefacto sufrió una nueva perforación con sección cilíndrica para su nuevo uso. Otro elemento reutilizado es el fragmento V-639-b, del cual quedaba sólo uno de los dos orificios de la perforación en "V", que se usó para pasar el hilo de sujeción.

\subsection{Estudio de la materia prima}

\section{Estudio óptico}

Siguiendo la metodología tradicional propuesta por Espinoza y Mann (1992), nos fue posible identificar la presencia de marfil de jabalí, cetáceo, hipopótamo y elefante (Tabla 2).

\begin{tabular}{|l|l|}
\hline Proboscidea & V596; V635; V752; V758; V773; V778; \\
& V784; V943; V968; V974; V1063; V1126; \\
& V1287; V1451; V1502; 1585; 3391; VS/N \\
\hline Hippopotamus anphibius & V601; V627; V639; V750; V985; V1440; \\
& V2212; V2941 \\
\hline Sus scrofa & V638; V1452 \\
\hline Physester macrocephallus & V625 \\
\hline No concluyente & \multicolumn{1}{|c|}{ V626 } \\
\hline
\end{tabular}

Tabla 2. Identificación de las diferentes piezas en base a la metodología visual establecida en 1992 por Espinoza y Mann. 


\section{Estudio por FTIR}

Para diferenciar entre elefante asiático y africano se procedió a analizar las muestras con un espectrómetro de infrarrojos. Los resultados de las siguientes piezas no fueron satisfactorios a causa de factores como la mala conservación, geometría compleja o uso de consolidantes durante la restauración: V-773, V-778, V-784, V-974, V-1126 y V-S/N. Por ello sólo se pudo proceder con 11 elementos. De acuerdo con la clasificación de la geometría de los espectros propuesta por A. Banerjee (Banerjee et al. 2008), que parte como criterio discriminante de la presencia en torno a $1100 \mathrm{~cm}^{-1}$ de un hombro característico en el marfil de elefante africano (L. africana africana), inexistente en el elefante asiático (E. maximus), se han definido (Tabla 3) 6 elementos de marfil de Elephasmaximus y 5 de Loxodonta africana africana.

\begin{tabular}{|l|l|}
\hline Elephas maximus & Loxodonta africana africana \\
\hline V635; V943; V968; V1287; V1451; V1585 & V596; V758; V1063; V1502; V3391 \\
\hline
\end{tabular}

Tabla 3. Identificación de las diferentes especies de elefante en base a la geometría del espectro.

\begin{tabular}{|l|l|l}
\hline Muestra & Tipo de marfil & Información adicional \\
\hline S1 & & Procedentes del mismo \\
S2 & & individuo \\
S3 & Loxodonta africana africana & \\
S4 & & \\
S6 & & \\
S7 & & Individuo joven \\
\hline S5 & Loxodonta africana africana & \\
\hline S8 & Elephas maximus & \\
S9 & & \\
\hline S10 & Hippopotamus amphibius & Fósil \\
\hline S11 & Hippopotamus amphibius & Fósil \\
\hline S12 & Palaeolosodon falconeri & \\
\hline S13 & palaeoloxodon antiquus & \\
\hline
\end{tabular}

Tabla 4. Tabla de muestras preliminares: Nomenclatura de las muestras conocidas estudiadas en el análisis preliminar.

Con el fin de asegurar la exactitud de la identificación se procedió a realizar un análisis de componentes principales que nos permitiera separar los conjuntos por las diferencias que presentaran en las características analizadas, para ello nos hemos basado en nuestra experiencia previa durante el análisis del marfil de Padru Jossu (Cerdeña, Italia), para lo cual se analizaron de forma preliminar muestras conocidas de elefantes asiático y africano, hipopótamo y marfil fósil de Palaeoloxodon antiquus y Palaeoloxodon falconerii, propiedad del Museo de Historia Natural de la Universidad de la Sapienza de Roma (Morillo et al., en prensa) (Fig. 15-16) (Tabla 4). 


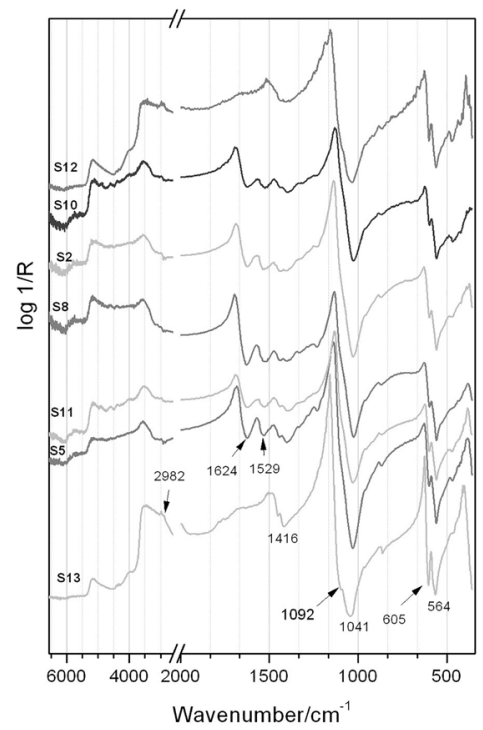

Fig. 15. FTIR preliminar: Espectros obtenidos del análisis preliminar

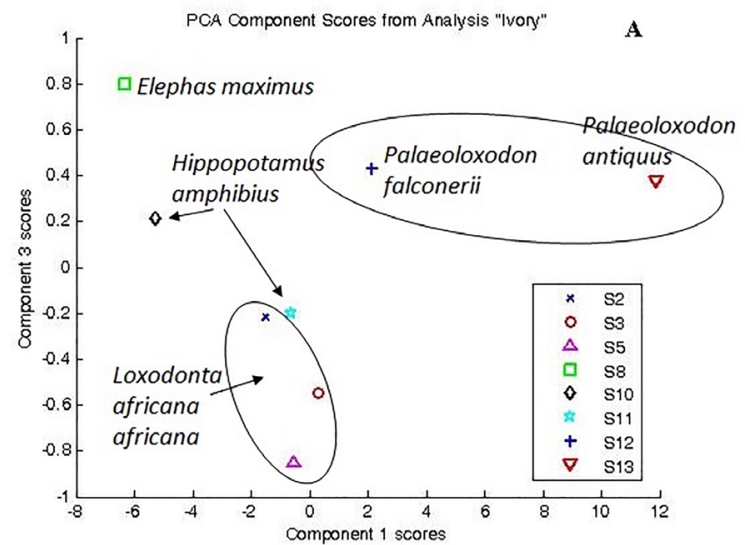

Fig. 16. PCA preliminar: Resultados del PCA realizado sobre los resultados de las muestras conocidas

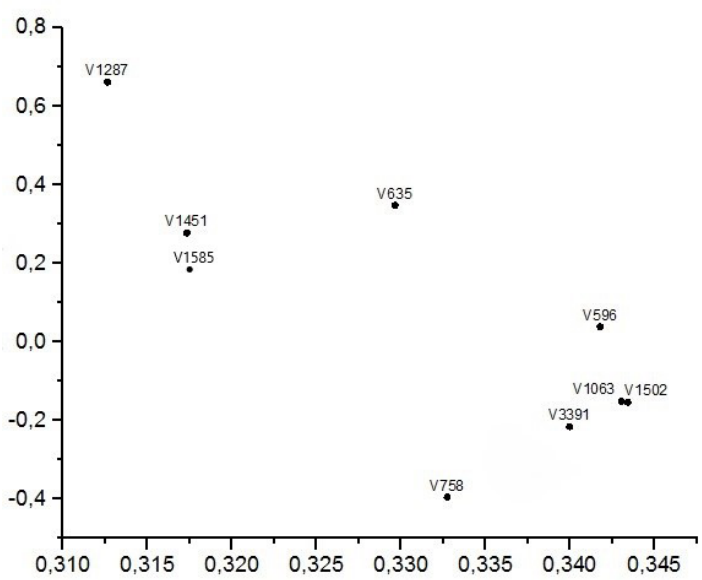

Fig. 17. Resultados del análisis de Componentes Principales (PCA). 
Debido a que el elemento diagnóstico se encuentra en la fase inorgánica (presencia o no del hombro en el pico de PO4 en torno a 1100 $\mathrm{cm}^{-1}$ ), ésta ha sido ponderada en el análisis, lo que resulta una ventaja para el caso de materiales degradados que ofrecen una significativa pérdida de la fase orgánica. Se han incluido como variables todos los puntos de la línea del espectro y el análisis ha ofrecido una varianza en el primer componente del 92,68\%, subiendo al $96,33 \%$ en los dos primeros y al 98,36\% considerando los tres primeros componentes.
En los resultados obtenidos (Fig. 17) el marfil correspondiente al elefante africano queda claramente agrupado en la esquina inferior derecha, debido a una mayor mineralización de la hidroxiapatita, mientras que el marfil de elefante asiático, que presenta una menor mineralización (Edwards et al. 2006), muestra una mayor dispersión, debido a que su mayor contenido orgánico hace que sea más susceptible a los procesos de degradación, lo que redunda en una menor homogeneidad en los resultados del análisis (Fig. 18-19).

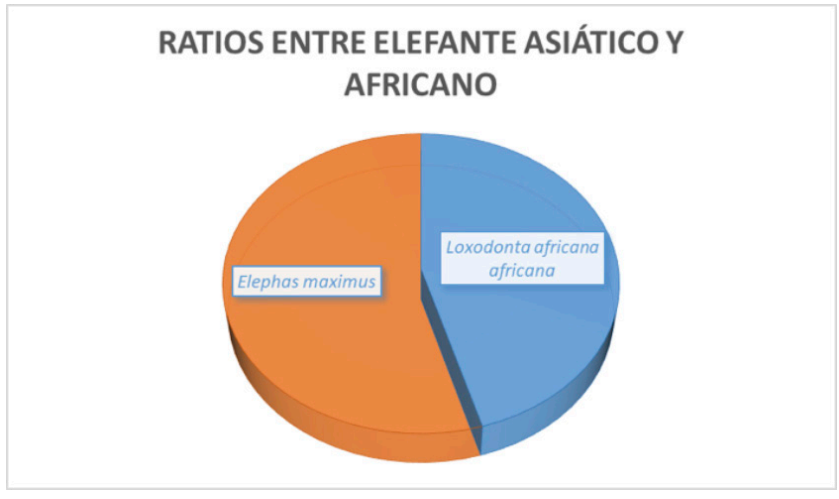

Fig. 18. Ratios entre elefante asiático e africano

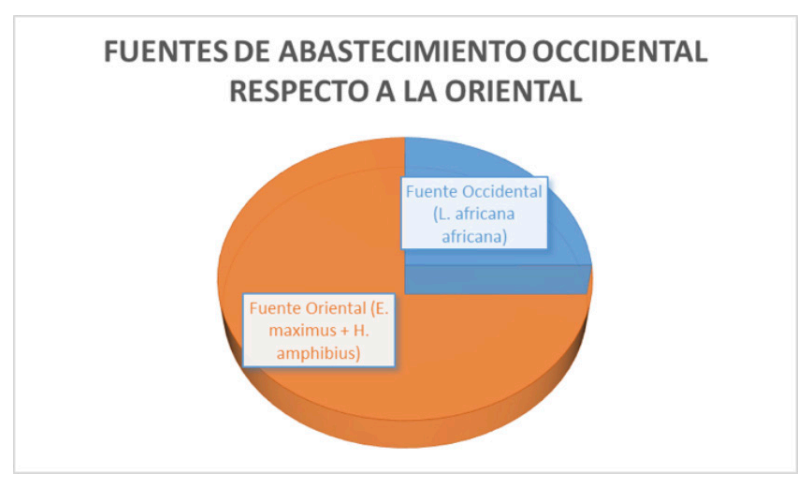

Fig. 19. Fuentes de abastecimiento occidental respecto a la oriental

\section{Discusión y conclusiones}

El estudio de los objetos de adorno personal en marfil del yacimiento del Cerro de la Virgen de Orce ha permitido identificar 2 categorías diferentes de adornos a partir de criterios morfofuncionales: colgantes y botones. Siguiendo variaciones morfológicas estas categorías se han dividido en grupos $\mathrm{y}$, donde ha sido necesario, en subgrupos.

Se ha podido establecer (Tabla 5) que en los niveles precampaniformes (Fase I), antes del 2500-2450, se usaban colgantes tra- pezoidales y botones de casquete de esfera. En el periodo campaniforme (Fase II), entre el 2500-2450 y el 2150, continúan presentes los botones de casquete de esfera y aparecen por primera vez los botones con "alitas laterales", los botones cónicos, los piramidales y los prismáticos (subgrupo 1). En la fase IIIA, Bronce Antiguo local, desde el 2150 hasta el 1950/1900, periodo previo al Bronce Argárico, encontramos un ejemplar tronco-piramidal, botones piramidales, botones con dobles extremidades y botones prismáticos de los subgrupos 1,2 y 3. 
Es importante observar que los objetos de adorno personal del Calcolítico y del Bronce del Cerro de la Virgen encuentran parecidos formales con los artefactos hallados en otros yacimientos españoles contemporáneos, demostrando la existencia de contactos entre las diversas comunidades culturales y el desarrollo de tradiciones coetáneas. Además las categorías de adornos del yacimiento del Cerro de la Virgen son formas típicas y recurrentes en la prehistoria reciente europea, mientras no conocemos paralelos para los colgantes. Los botones derivados de la esfera están presentes en una zona geográfica muy amplia, conociéndose en la isla de Cerdeña, en Francia Meridional, en Centroeuropa, en la Península Ibérica y en los países Nórdicos (Guilaine 1963; Ferrarese Ceruti 1974; Pérez y Lopez de Calle, 1986; Uscatescu, 1992; Pau, 2016). Es complicado hacer una diferenciación por grupos, teniendo en cuenta que muchos autores hablan en general de botones hemisféricos. Centrándonos en España, los botones del Cerro de la Virgen encuentran parecidos formales con uno de los botones recuperados en el yacimiento de los Castillejos de Montefrío (Pau 2016; Pau y Molina 2015) y con el botón de Moncín en Zaragoza
(Rodanés 1987: Lámina 30, 61. 3). J. Guilaine y J. Arnal situaron el origen de los botones de casquete esférico en fechas anteriores al 2000 a.C., sin calibrar (Guilaine 1963; Arnal 1973), mientras que A. Uscatescu, en relación con la Península Ibérica, los coloca entre el Calcolítico y el Bronce Antiguo (Precampaniforme y Campaniforme) y añade que pervivieron hasta el Bronce Medio del valle del Ebro (Uscatescu 1992). En nuestro caso de estudio el botón V-3391 fue hallado en un estrato precampaniforme mientras que el V-2941, de dimensiones mayores, se sitúa en la fase inicial del periodo propiamente campaniforme caracterizado por la presencia de la típica cerámica. En cualquier caso se situarían en fechas cercanas al 2500 CAL a.C. El botón con "alitas laterales" V-1440 encuentra profundas analogías morfológicas con dos artefactos de Los Castillejos de Montefrío (Pau 2012, 2016; Pau y Molina 2015). Los botones a doble punta encuentran paralelos en adornos campaniformes franceses e italianos que pertenecen a una fase campaniforme considerada Bronce Antiguo local (Pau 2012) y los dos elementos del Cerro de la Virgen se colocan en el Bronce Antiguo.

\begin{tabular}{|c|c|c|c|c|c|c|c|c|}
\hline Periodo & Schüle & $\begin{array}{l}\text { Intervención } \\
\text { arqueológica }\end{array}$ & Objetos de adorno & & Categoría & Grupo & Subgrupo & $\begin{array}{l}\text { Total } \\
\text { artefactos }\end{array}$ \\
\hline \multirow[t]{2}{*}{ Precampaniforme } & \multirow[t]{2}{*}{ I } & 1963 & Colgante trapezoidal & V. 2212 & I & 1 & & \multirow[t]{2}{*}{2} \\
\hline & & 1965 & Botones de casquete esférico & V. 3391 & II & 1 & & \\
\hline Campaniforme & II & 1970 & Botones de casquete esférico & V. 2941 & II & 1 & & 1 \\
\hline \multirow{4}{*}{$\begin{array}{l}\text { Campaniforme } \\
\text { Inicial/Campaniforme } \\
\text { Pleno }\end{array}$} & \multirow[t]{4}{*}{ IIA/IIB } & 1965 & Botones con alitas laterales & V.1440 & II & 2 & & \multirow[t]{4}{*}{4} \\
\hline & & 1965 & Botones cónicos & V. 1287 & II & 4 & & \\
\hline & & 1965 & Botones piramidales & V. 1063 & II & 5 & & \\
\hline & & 1965 & Botones prismáticos & V. 1585 & II & 7 & 1 & \\
\hline \multirow[t]{2}{*}{ Campaniforme Pleno } & \multirow[t]{2}{*}{ IIB } & 1965 & Botones piramidales & V. 1452 & II & 5 & & \multirow[t]{2}{*}{2} \\
\hline & & 1965 & Botones prismáticos & V. 1502 & II & 7 & 1 & \\
\hline $\begin{array}{l}\text { Campaniforme } \\
\text { Pleno/Campaniforme } \\
\text { Final }\end{array}$ & IIB/IIC & 1965 & Botones cónicos & V. 1451 & II & 4 & & 1 \\
\hline \multirow{6}{*}{$\begin{array}{l}\text { Campaniforme Final/ } \\
\text { Bronce Antiguo Local }\end{array}$} & \multirow[t]{6}{*}{ IIC/IIIA } & 1965 & Botones piramidales & V. 968 & II & 5 & & \multirow[t]{6}{*}{6} \\
\hline & & 1965 & Botones piramidales & V. 784 & II & 5 & & \\
\hline & & 1965 & Botones piramidales & V. 985 & II & 5 & & \\
\hline & & 1965 & Botones tronco-piramidales & V. 1126 & II & 6 & & \\
\hline & & 1965 & Botones prismáticos & V. 974 & II & 7 & 1 & \\
\hline & & 1965 & Botones prismáticos & V. 943 & II & 7 & 1 & \\
\hline \multirow{2}{*}{ Post Campaniforme } & \multirow[t]{2}{*}{ III } & 1965 & Botón con doble extremidades & V. 750 & II & 3 & 1 & \multirow[t]{2}{*}{2} \\
\hline & & 1965 & Botón con doble extremidades & V. 601 & II & 3 & 2 & \\
\hline \multirow[t]{10}{*}{ Bronce Antiguo Local } & \multirow[t]{10}{*}{ IIIA } & 1965 & Colgante irregular & V. 758 & $\mathrm{I}$ & 2 & & \multirow[t]{10}{*}{10} \\
\hline & & 1965 & Botones piramidales & V. 625 & II & 5 & & \\
\hline & & 1965 & Botones piramidales & V. 773 & II & 5 & & \\
\hline & & 1965 & Botones piramidales & V. 638 & II & 5 & & \\
\hline & & 1965 & Botones prismáticos & V. 627 & II & 7 & 1 & \\
\hline & & 1965 & Botones prismáticos & V. 635 & II & 7 & 1 & \\
\hline & & 1965 & Botones prismáticos & V. 778 & II & 7 & 1 & \\
\hline & & 1965 & Botones prismáticos & V. 639-1 & II & 7 & 3 & \\
\hline & & 1965 & Botones prismáticos & V. 639-2 & II & 7 & 3 & \\
\hline & & 1965 & Botones prismáticos & V. 626 & II & 7 & 2 & \\
\hline \multirow[t]{2}{*}{ Bronce Argárico } & \multirow[t]{2}{*}{ IIIB } & 1965 & Botones piramidales & V. 596 & II & 5 & & \multirow[t]{2}{*}{2} \\
\hline & & 1965 & Botones prismáticos & V. 752 & II & 7 & 1 & \\
\hline
\end{tabular}

Tabla 5. Cronología de los objetos de adorno en marfil del Cerro de la Virgen. 
Los botones cónicos los encontramos en los Alpes, en Italia, en España, en el sureste francés, en Malta, en Centroeuropa, en las islas británicas, en Suecia, en Lituania, en Rusia y en Irán (Uscatescu 1992: 102-103). Los botones cónicos normalmente se hallan en asociación con cerámica campaniforme, aunque muchos aparecen en contextos de finales del III milenio en asociación a ésta (Delibes 1977: 177; Uscatescu 1992: 37, 62). Sin embargo en el Cerro de la Virgen los botones de forma cónica aparecen desde las primeras fases del desarrollo del fenómeno campaniforme (desde el 2550). Los botones piramidales no sólo los encontramos en España, sino también en Alemania, Suecia, Irlanda y Gran Bretaña (Uscatescu, 1992: 103). Los botones del Cerro de la Virgen encuentran parecidos formales con los mismos artefactos en marfil recuperados en Los Castillejos de Montefrío (Pau, 2016) y con algunos ejemplares del yacimiento de Falguera (Alcoi, Alicante) manufacturados en marfil y en concha (Pau 2016). Según A. Uscatescu los botones piramidales de base rectangular aparecen en la Península Ibérica en momentos avanzados del III milenio a.C., aunque la autora subraya que existen pocos de estos elementos en asociación con cerámica campaniforme, el resto se pueden fechar en el Bronce Antiguo o principios del Bronce Medio. En este caso los adornos del Cerro de la Virgen confirman esta atribución entre el Campaniforme y el Bronce Inicial (V-1.452, V-968, el V-1126 el V-784 y el V-985, V-625, V-773 y V-638). Los botones prismáticos se localizan en Mallorca, Cataluña, sureste de Francia y sur de Polonia, con la mayor concentración en la Península Ibérica (Uscatescu 1992: 75, 103, 104), por lo que se ha planteado su origen en el Pirineo oriental (Pérez y Lopez de Calle, 1986; Ontañon 2002: 110). La mayoría de los autores considera que este tipo de botones pertenece a un momento avanzado del fenómeno campaniforme y pervive hasta la Edad del Bronce (Arnal 1973: 222; Harrison 1977: 87-90, Uscatescu 1992: 80), llegando incluso en el Sudeste a estar presente en las sepulturas argáricas (López 2006: 109-110, 2011: 473). R. Ontañón (2002: 110) recuerda que se han documentado algunos botones asociados a estilos campaniformes antiguos (en dos dólmenes de Tarn-et-Garonne y en el de Pagobakoitza) y en otros tipos de contextos como Font Juvénal (Conques, Aude), con cerámica campaniforme de estilo pirenaico (Ontañón 2002: 110). De hecho, los botones del Cerro de la Virgen aparecen desde el momento de auge del Campaniforme (Fase IIB), hasta el Bronce Inicial. Los elementos del Cerro de la Virgen recuerdan los botones de Los Castillejos de Montefrío y los artefactos de la Figuera y de Gatz en la comunidad Valenciana (Pau 2016). Los subgrupos 2 y 3 de los botones prismáticos, para los que no conocemos paralelos, sí pertenecen al Bronce Inicial.

Desde el punto de vista de la técnica de fabricación, se han podido observar generalmente las huellas de las últimas fases de elaboración y de regulación de la superficie de la pieza y también los métodos utilizados para perforar los artefactos, mostrando en la mayoría de los casos un gran cuidado en la ejecución con óptimos resultados finales, aunque parece que algunos de los adornos se utilizaron sin haber sido pulimentados. No se han encontrado materiales en bruto o en fase de elaboración, por lo tanto no tenemos información de las primeras fases de manufactura, aunque las fases se conocen gracias a otros estudios, por ejemplo en España en el Cerro de la Encantada de Granátula de Calatrava (Fonseca 1988: 165) y en el Cerro de El Cuchillo de Almansa (Barciela 2002: 79-81, 2007). El primer estadio consistiría en un seccionamiento transversal del colmillo, en rodajas, mediante el aserrado de la pieza o con un sistema de entallado circular. Después se pasaría a un segundo estadio, con la extracción de los preparados, que son las bases para la realización de las piezas a través del sistema del doble aserrado. En una tercera fase se transformarían las matrices mediante su aserrado, calibrando la pieza. Una vez alcanzada la morfología deseada se pasaba a la perforación. El último paso sería el acabado de la pieza con el pulido. Desde el Campaniforme la reutilización de los adornos implicó a veces su recorte en ciertas partes sin pulimento posterior.

El uso de los colgantes (Categoría I) está comprobado por evidencias arqueológicas y paralelos etnográficos, además del análisis traceológico y morfológico de las piezas. El uso como botones del resto de los adornos está sugerido por las evidentes analogías formales con los objetos que actualmente definimos como "botones". Sin embargo, hay diferentes interpretaciones en relación con la funcionalidad de estas piezas: botones, cuentas, colgantes, lúnulas, separadores de collar, adornos para vestidos, elementos que formaban los pectorales o elementos que venían situados en la cuerda de los arcos para mejorar el disparo 
de la flecha (Uscatescu 1992). Lo cierto es que se han encontrado, en otros contextos, varios indicios que atestiguan su uso en relación con las vestimentas, sea para abrocharlas o simplemente decorarlas, como la posición de las piezas en relación con los esqueletos encontrados en posición primaria, y también las manchas de colorante rojo (cinabrio o almagra) procedentes posiblemente del colorante utilizado para teñir las prendas de vestir (López 2011). En nuestro caso, este uso se adapta perfectamente a la morfología de la pieza, la disposición de los elementos de suspensión, el tamaño y sus características. De hecho, las trazas de uso muestran el paso de un hilo para ser cosido a la vestimenta. Sólo el estudio de estos parámetros en el adorno V-2941 nos ha llevado a plantear que podría tratarse no de un elemento para ser cosido sino para ser colgado. Gracias al estudio traceológico realizado en los botones se han identificado manchas de pulido, zonas desgastadas muy suaves al tacto, seguramente por el roce con las vestimentas, en toda la superficie de algunos y localizadas en los márgenes en otros. Además, es importante el hecho de que diversos botones examinados presentan la perforación original fracturada, apareciendo una segunda o más perforaciones para poderlos mantener funcionales, implicando su reutilización como colgantes.

Estudiando la materia prima hemos podido determinar que la mayoría de estos objetos se realizaron en verdadero marfil. Entre el resto de los elementos destaca que dos botones piramidales, categoría 2 grupo 5, uno de época campaniforme (V-1452) y otro del Bronce Antiguo (V-638), fueron manufacturados a partir de dos grandes colmillos de jabalí. Estos elementos demuestran que también se dio un aprovechamiento de materias primas a las que se podía acceder con relativa facilidad para conseguir objetos de apariencia similar que, sin duda, conferían ideológicamente un cierto prestigio. Por el contrario la mayoría de los objetos aquí examinados proceden de fuentes de aprovisionamiento lejanas, lo que se puede aplicar tanto al marfil de elefante como al de hipopótamo. Incluso el objeto de adorno confeccionado sobre marfil de cetáceo (Physester macrocephallus), el botón piramidal V-625 del Bronce Antiguo, implica una fuente de aprovisionamiento lejana, dada la distancia al mar del Cerro de la Virgen.

Con respecto al hipopótamo, esta especie estaba presente en momentos cronológicos más o menos coetáneos en el Delta del Nilo y en el área siria, principalmente en los valles del Amuq y el Orontes (Krzyszkowska 1990), donde era el tipo de marfil más utilizado como materia prima para objetos suntuarios y simbólicos (Krzyskowska 2001). Asimismo, se habla de su presencia en el llamado Sahara verde, en una fase anterior a la que nos ocupa, por lo que no se puede descartar que aún existieran comunidades de hipopótamos en el Hoggar, al sur de Argelia (Schuhmacher 2012). Sin embargo, la ausencia de materiales en marfil de hipopótamo en estas fechas en el Magreb podría llevar a descartar esta zona como fuente de abastecimiento. Evidentemente, si se considerara la única fuente de abastecimiento factible el Próximo Oriente, eso sería un apoyo más a lo que ha sido planteado en relación con la circulación del marfil asiático durante el Calcolítico hacia la Península Ibérica (Schuhmacher 2012). La mayoría de los elementos realizados en marfil de hipopótamo del Cerro de la Virgen pertenecen al Bronce Antiguo (más del 60\%) en consonancia con lo propuesto por Schuhmacher (2012), pero las afirmaciones de este autor deben matizarse a la luz de la presencia de varias piezas pertenecientes al Calcolítico del Cerro de la Virgen, y especialmente por la atribución de la pieza V-2212 a la fase precampaniforme. Como hemos dicho es posible que esta pieza V-2212 sea un fragmento de un ídolo en dos piezas similar al del Malagón (Arribas 1977; Altamirano 2013). La similitud de los ídolos "antropomorfos" con modelos egeos y orientales en fechas tempranas nos podrían hacer pensar una vez más en contactos con el Mediterráneo Central y Oriental, aunque ya hace tiempo se había señalado que la similitudes en estos ídolos no son tan grandes como para hablar de influencias directas (Usai 199293), sino más bien de un entorno Mediterráneo abierto a la circulación e ideas inmateriales en muchas direcciones.

En cuanto a la tipología, mientras el artefacto referido anteriormente (V-2212) pertenece a la categoría I grupo 1, los otros 7 adornos son de la categoría 2, 1 del grupo 1 (V-2941), 1 del grupo 2 (V-1440), 1 del grupo 3 (subgrupo 2) (V-601), 1 del grupo 5 (V-985) y 3 elementos del grupo 7, 2 del subgrupo 1 (V-650, V-627) y 2 del subgrupo 3 (V-639-a y V-639-b). Realmente casi todos los grupos tipológicos incluyen elementos realizados en marfil de hipopótamo lo que implica que, o bien todos estos grupos se realizaban también en la zona de procedencia del marfil o bien, más probablemente, aquí llegaba la materia prima en bruto. 
Aun en este caso, un interrogante que se nos plantea es si alguno de los objetos pudo llegar ya manufacturado al Cerro de la Virgen, incluso desde yacimientos cercanos.

Para el caso del elefante debemos distinguir dos áreas de abastecimiento bien diferenciadas, el Norte y posiblemente el Este de África para el elefante africano de sabana (Loxodonta africana africana) (Ansell 1971), y Siria para el elefante asiático, cuya presencia ha sido ya confirmada en varias zonas del Occidente mediterráneo (Krzyszkowska 1990; Schuhmacher y Banerjee 2012). En el Cerro de la Virgen, de hecho, existen objetos manufacturados tanto sobre colmillos de elefante africano como de elefante asiático. Estos últimos plantean el problema de su procedencia tan lejana que implicaría contactos desde el Calcolítico con el Próximo Oriente, como ya hemos señalado en relación con el marfil de hipopótamo. Con respecto al uso de marfil de elefante africano, probablemente se inscribe en un contexto de circulación de diferentes materias primas desde el norte de África, entre las que destacan los huevos de avestruz (Harrison 1977) y, por supuesto, el marfil de elefante de sabana que resulta mayoritario en los yacimientos calcolíticos del Oeste de la Península Ibérica pero no en el Sur y especialmente en el Sudeste donde se constata el marfil de elefante asiático (Schuhmacher et al. 2009; Schuhmacher 2012). No obstante, la existencia de comunidades de Loxodonta africana africana en torno al Cuerno de África hasta fechas recientes, hace que no sea descartable el aporte de cierta cantidad de materia prima procedente de esta zona del África oriental. Una vez más, debemos hacer hincapié en la necesidad de estudios isotópicos que, como en el caso del hipopótamo antes mencionado, resultan la única forma fiable de establecer claramente la procedencia del material arqueológico (Coutu et al. 2016).

Como hemos dicho, a raíz de hallazgos de otros yacimientos (Cerro de la Encantada de Granátula de Calatrava y el Cerro de El Cuchillo de Almansa) (Fonseca 1988: 165; Barciela 2002: 79-81, 2007) habría que pensar que llegarían los propios colmillos como soporte para la realización de los diferentes objetos de adorno. La presencia de colmillos completos está sobradamente atestiguada tanto en la Península Ibérica (Schuhmacher 2012; García et al. 2013) como en Próximo Oriente, en las ciudades de Ebla (Peyronel 2016) y Alalakh (Yener 2007). Además han sido documentados en el sur de la Península Ibérica importantes talleres de realización de objetos en marfil (Nocete et al. 2013; Lizcano et al. 2009).

En el Cerro de la Virgen a nivel cronológico no se observa ninguna preferencia en el uso de uno o de otro tipo de marfil de elefante, a diferencia de lo que se ha propuesto para otros yacimientos con el cese en la llegada de marfil asiático a la Península Ibérica en la Edad del Bronce (Schuhmacher 2011, 2012). Por el contrario el caso de estudio nos refiere un equilibrio total en los objetos realizados con una u otra materia prima, tanto en el Calcolítico como en el Bronce Antiguo, aunque la muestra se reduzca a 11 objetos discriminables.

En relación con la tipología, hemos constatado que de los 5 objetos de adorno manufacturados en Loxodonta africana africana, 1 elemento pertenece a la categoría 1 grupo 2 (V-758), 4 adornos a la categoría 2, 1 al grupo 1 (V-3.391), 2 al grupo 5 (V-596; V-1063) y 1 al grupo 7, subgrupo 1(V-1502). Los 6 elementos realizados en marfil de Elephas maximus son todos de la categoría 2. De ellos, 2 pertenecen al grupo 4 (V-1287; V-1451), uno al grupo 5 (V-968) y 3 al grupo 7 subgrupo 1 (V-635, V-943, V-1585). Como se ha dicho en el caso de los elementos sobre marfil de hipopótamo, la enorme variabilidad confirma que lo que circuló fue la materia prima, probada por los hallazgos ya referidos de colmillos completos (Fonseca 1988: 165; Barciela 2002: 79-81, 2007).

Tanto la reutilización de muchos de los objetos de adorno como la procedencia exógena de la materia prima sugiere que los botones no serían simplemente "objetos funcionales", sino que su uso implicaría la exhibición de roles personales en los que el acceso a ciertas formas y soportes generaría y reproduciría el prestigio de la persona que los portase. Estos objetos pudieron ser intercambiados durante ceremonias sociales y fiestas para consolidar alianzas entre familias. Incluso los botones realizados sobre colmillos de jabalí pudieron relacionarse con ese prestigio al proceder de animales de gran talla cuya caza, como la de los hipopótamos o elefantes, fue sin duda una empresa arriesgada. Además, dadas las dificultades para distinguir el origen del elemento de marfil a simple vista, las implicaciones ideológicas serían las mismas. Un aspecto importante a considerar es que, a diferencia de otros casos (Valera et al. 2015), los contextos en que se hallaron los objetos son domésticos y no funerarios, lo que demuestra la importancia de la exhibición de estos objetos en vida. 


\section{Apéndice:}

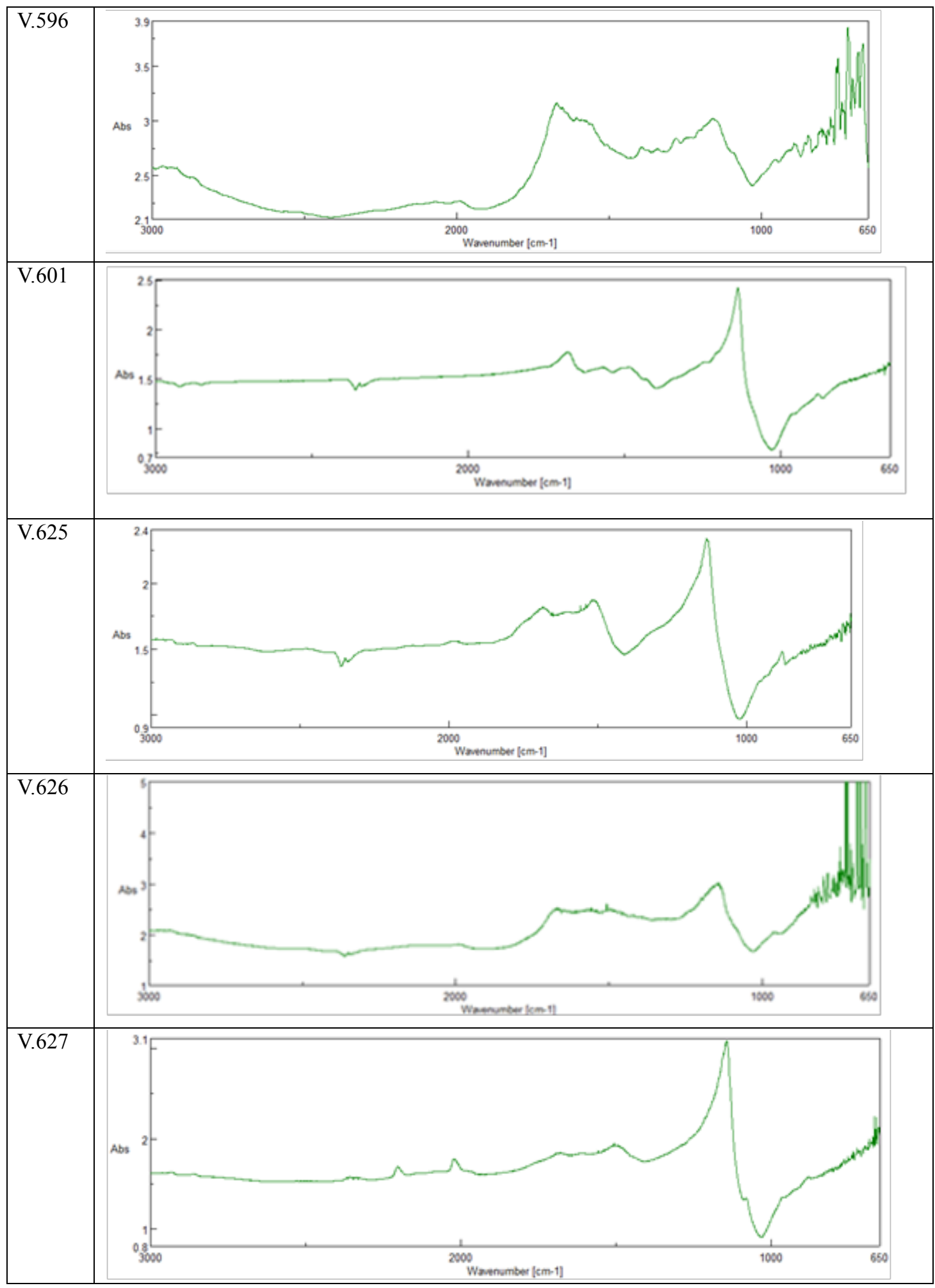




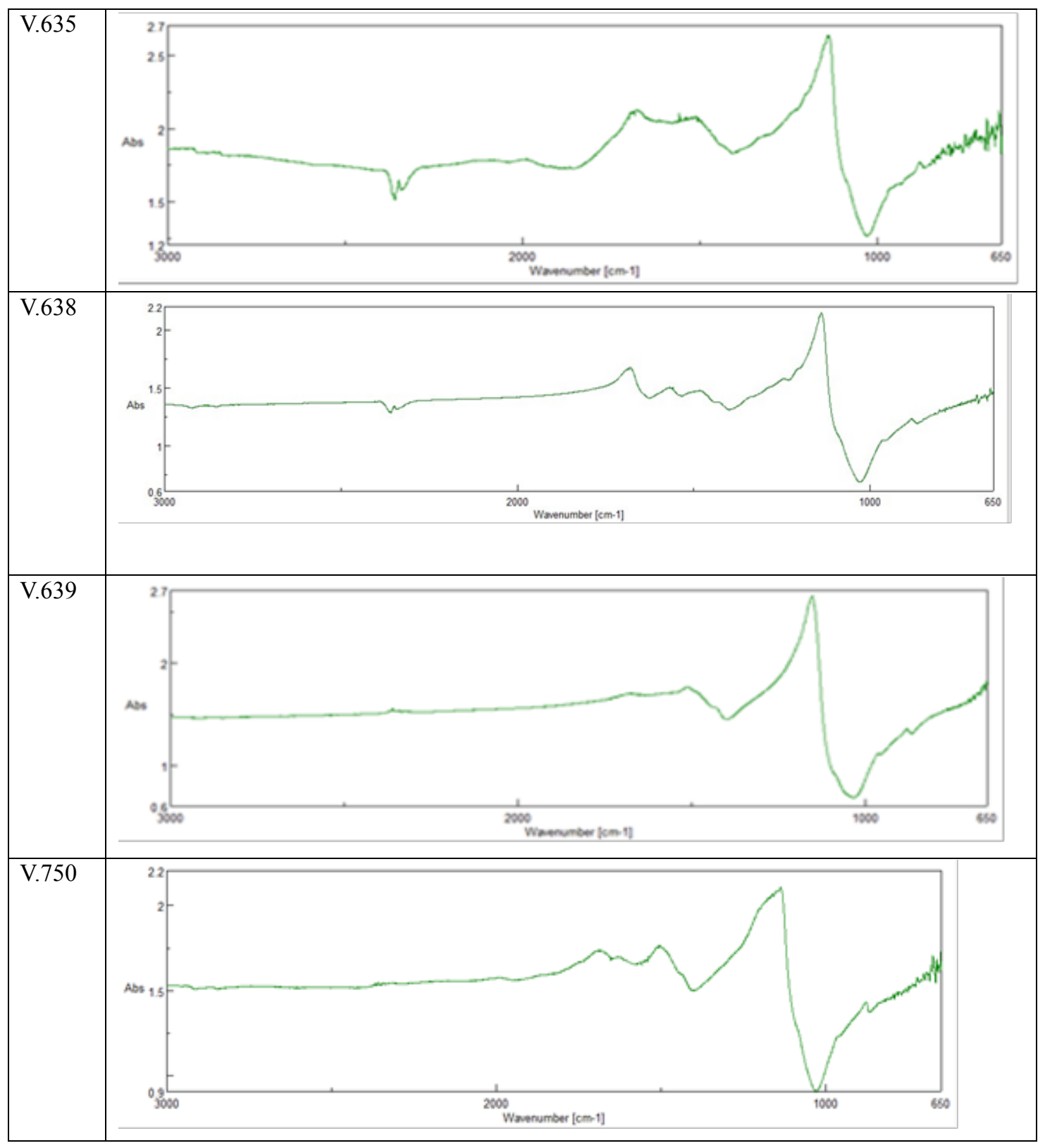




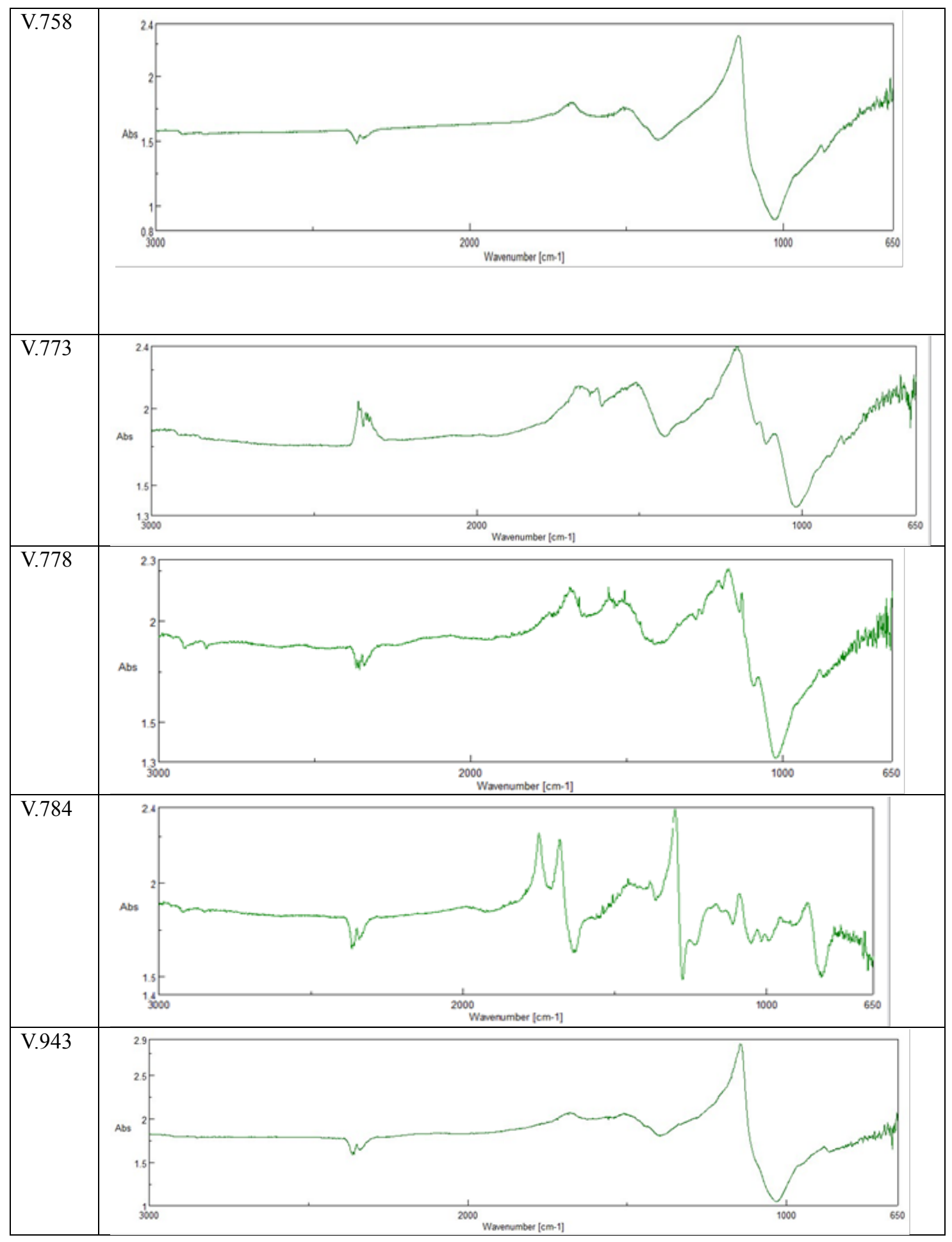




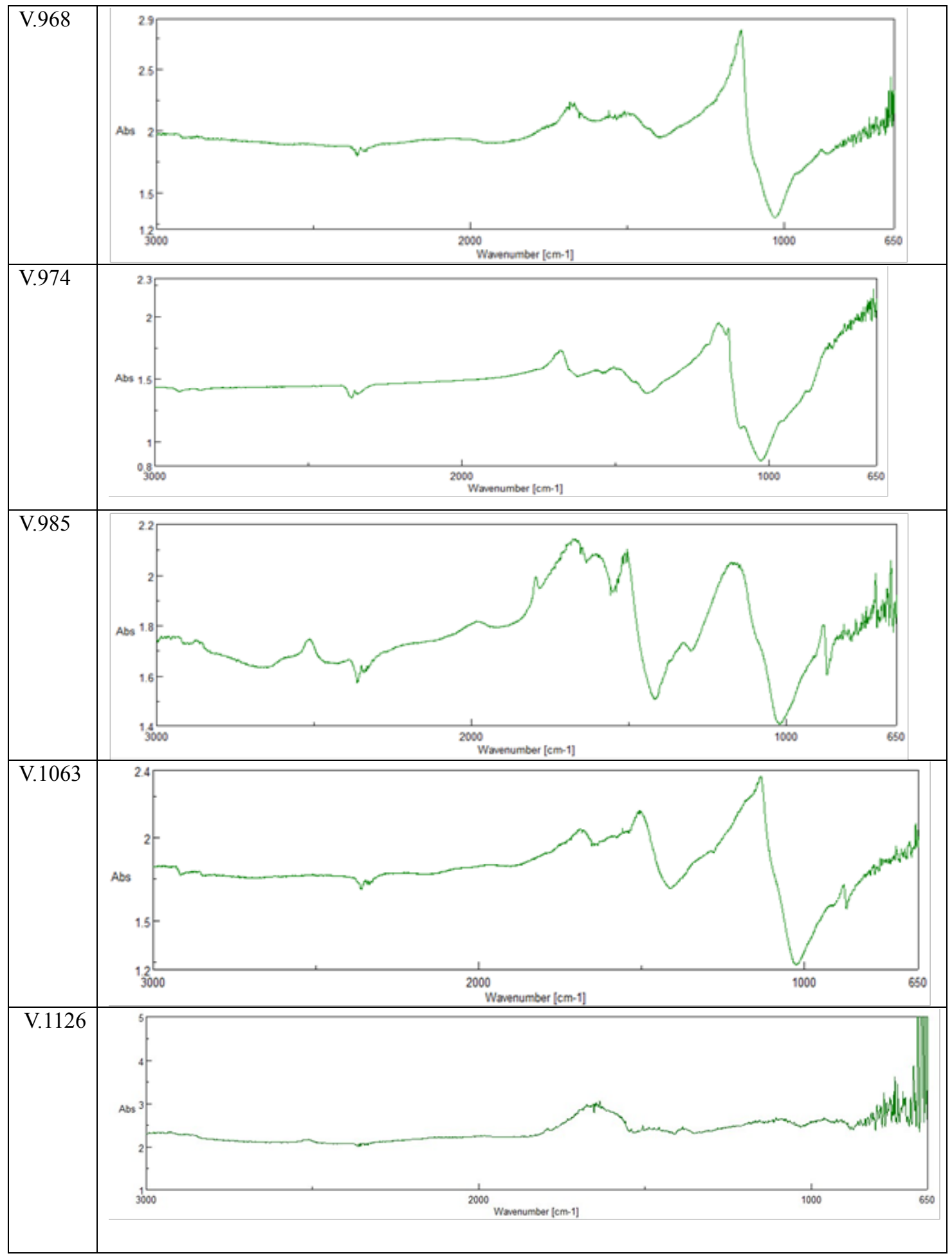



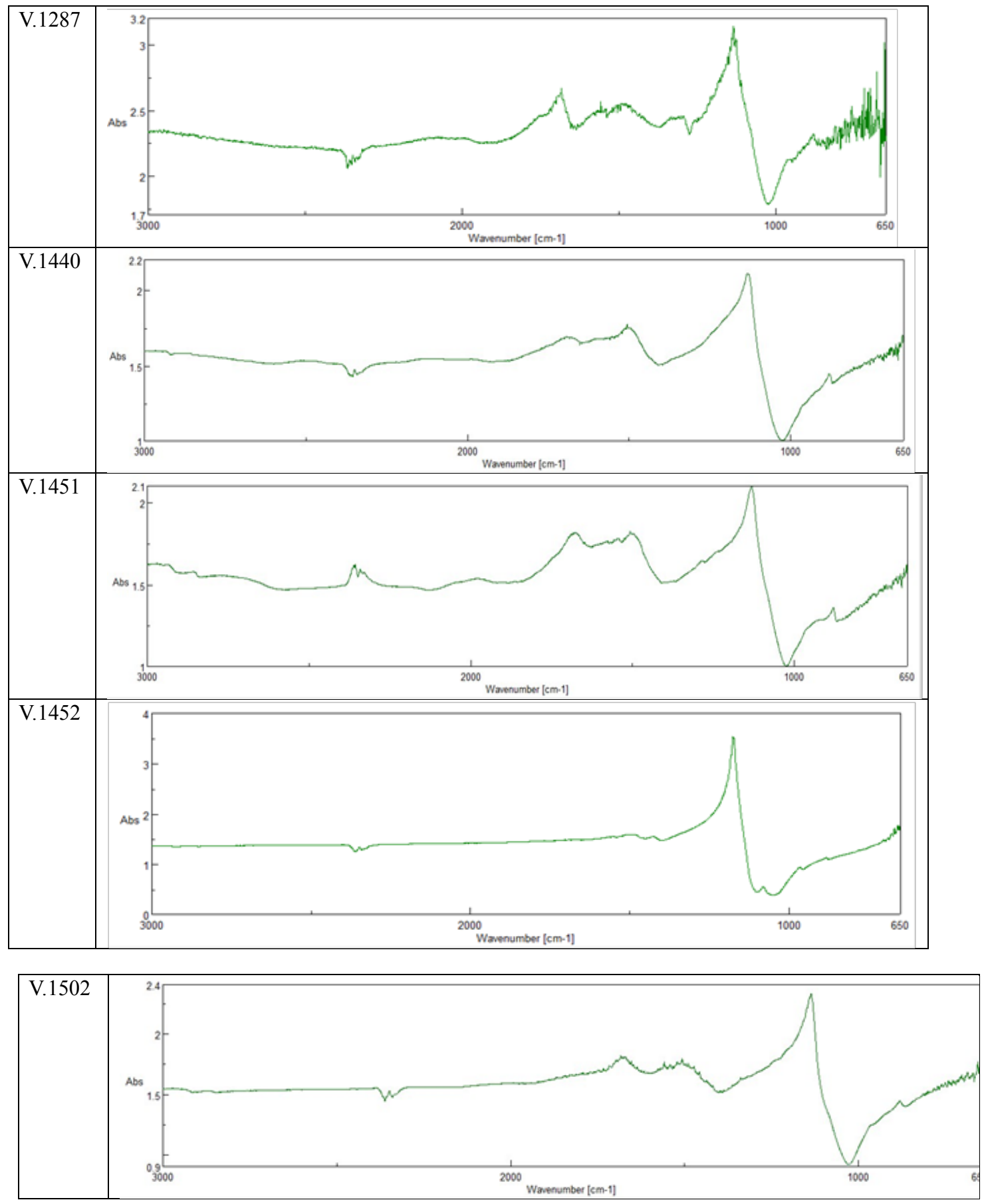


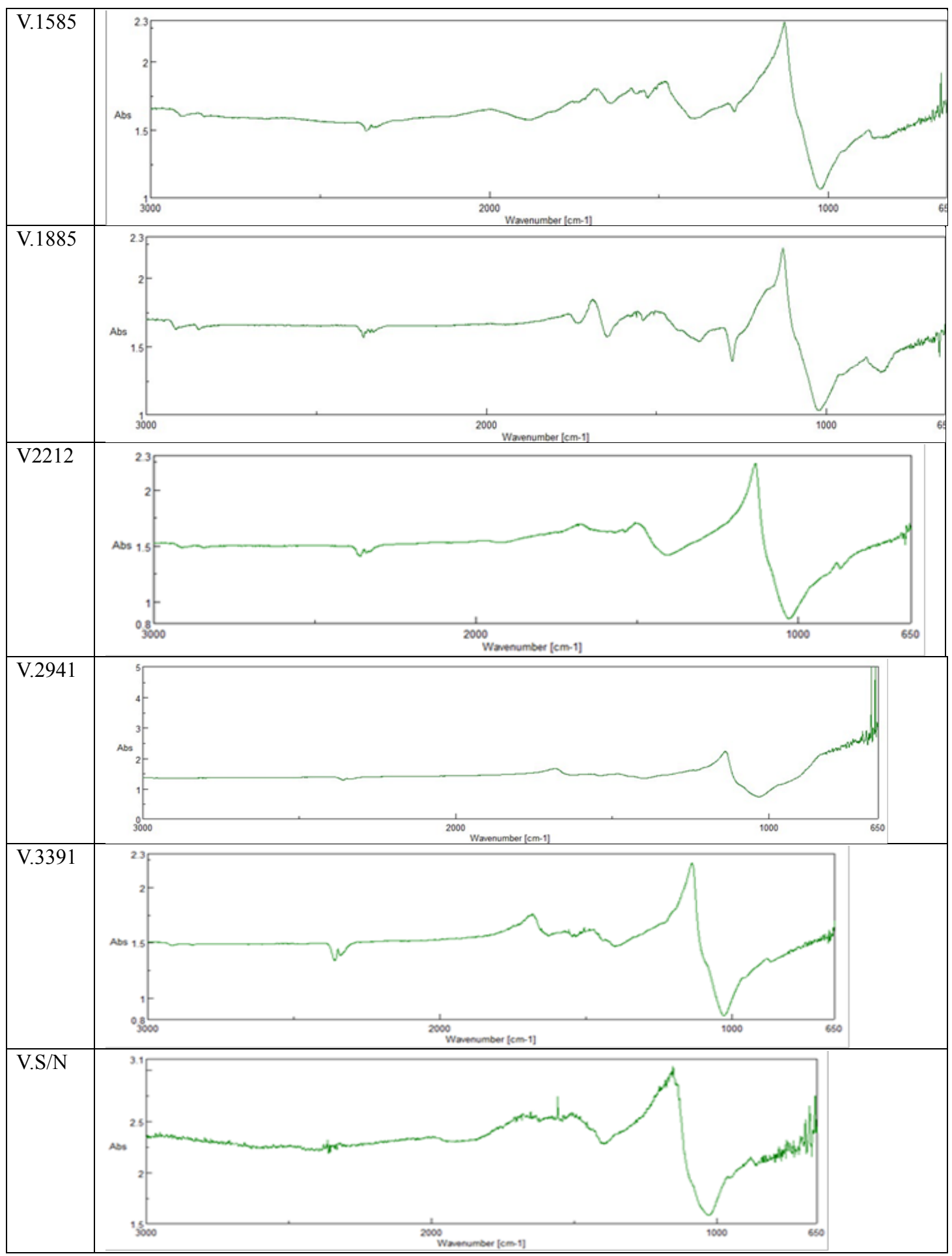




\section{Bibliografía}

Afonso, J. A. (1993): Aspectos técnicos de la producción lítica de la Prehistoria Reciente de la Alta Andalucía y el Sureste. Tesis doctoral, Universidad de Granada, Granada.

Albéric M., Dean M.N., Gourrier A., Wagermaier W., Dunlop J.W.C., Staude A., Fratzl, P. y Reiche, I. (2017): Relation between the Macroscopic Pattern of ElephantIvory and Its Three-Dimensional MicroTubularNetwork. PLOS ONE, 12, 1: 1-22.

Altamirano, M. (2013): Hueso, hasta, marfil y concha: aspectos tecnológicos y socioculturales durante el III y II milenio a. C. en el Sur de la Península Ibérica. Tesis doctoral, Universidad de Granada, Granada.

Altamirano, M. (2014): Hueso, hasta, marfil: manufactura de artefactos durante el III milenio A.C. en el poblado de los Castillejos (Montefrío, Granada). Saguntum, 46: 21-40.

Ansell, W.F.H.(1971): Order Proboscidea. The mammals of Africa: an identification manual. (J. Meester, H. Setzer, eds.), Smithsonian Inst. Press, Washington, D.C.: Part II.

Arnal, J. (1954): Les boutons perforés en V. Bulletin de la Société préhistorique française, tome 50, 5-6: $255-268$

Arnal, J. (1973): Sur les Dolmens et Hypogées des Pays Latins: Les V-Boutons. Megalithic Graves and Ritual. Papers presented at the III Atlantic Colloquium (G. Daniel, P. Kjaerum, eds.), Jutland Archaeological Society, Publications XI, Kobenhavn: 221-227.

Arribas, A. (1977): El ídolo de El Malagón (Cullar Baza, Granada). Cuadernos de Prehistoria de la Universidad de Granada, 2: 63-86.

Banerjee, A. y Huth, J. (2012): Investigation of Archaeological Ivory. Elfenbeinstudien. Faszikel 1: Marfil y elefantes en la Península Ibérica y el Mediterráneo occidental. Actas del coloquio internacional en Alicante el 26 y 27 de noviembre 2008 (A. Banerjee, J.A. López Padilla, T.X. Schumacher, eds.). Iberia Archaeologica, 16, 1, Mainz: 15-28.

Banerjee, A. Bortolaso, G. y Dindorf, W. (2008): Distinction between African and Asian ivory. Elfenbein und Artenschutz. INCENTIVS - Tagungsbeiträge der Jahre (2004-2007), Bundesamt für Naturschutz 28, Bonn: 37-49.

Barge, H. (1982): Les parures du Néolithique ancien au début de l’Âge des Métaux en Languedoc. Centre National de la Recherche Scientifique, Paris.

Barciela V. (2002): Intercambio y trabajo del marfil en un poblado del edad del bronce: el Cerro de El Cuchillo (Almansa, Albacete). Bolskan, 19: 75-84.

Barciela, V. (2007): Los elementos de adorno de El Cerro de El Cuchillo (Almansa, Albacete), Análisis tecnológico y funcional. Instituto de estudios Albatecenses "Don Juan Manuel”, Albacete.

Barciela, V. (2008): Adorno y simbolismo. Los adornos personales del Neolítico y Eneolítico en Villena (Alicante). Fundación Municipal "José María Soler, Villena.

Becker, H. y Brandherm, D. (2010): Eine Testmessung zur magnetischen Prospektion am Cerro de la Virgen 1998 (Prov. Granada, Spanien). Beiträger zur Vor- und Frühgeschichte der Iberischen Halbinsel und Mittleleuropas. Studien in honorem Philine Kalb (T. Armbruester y M. Hegewish, eds.), Studien zur Archäologie Europas 11, Verlag Dr. Rudolf Habelt GmbH, Bonn: 267-272.

Bonnardin, S. (2009): La parure funéraire au Néolithique ancien dans les Bassins parisiens et rhénans. Rubané, Hinkelstein et Villeneuve-Saint-Germain. Mémoire de la Société Préhistorique Française, Paris.

Boessneck, J. (1969): Restos óseos animales del Cerro de la Virgen, en Orce y Cerro del Real, en Galera Granada. Noticiario Arqueologico Hispanico, X-XI-XII: 172-189.

Botella, M. (1976): Antropología de las poblaciones argáricas. Tesis Doctoral, Universidad de Granada, Granada.

Botella, M. y Souich, Ph. du. (1975): Estudio antropológico de los pobladores argáricos del Cerro de la Virgen Orce (Granada). Instituto F. Olöriz, Universidad de Granada, Granada.

Bubner, T. (1977): Das Glockenbechervolk auf der Iberischen Halbinsel. Universität Freiburg, Freiburg.

Buxó, R. (1997): Arqueología de las plantas. La explotación económica de las semillas y los frutos en el marco mediterráneo de la Península Ibérica. Crítica, Barcelona.

Cámara, J.A. y Molina, F. (2009): El análisis de la ideología de emulación: el caso de El Argar. Cuadernos de Prehistoria y Arqueología de la Universidad de Granada, 19: 163-194.

Carrillero, M. (1992): El fenómeno Campaniforme en el sureste de la Península Ibérica. Servicio de Publicaciones Universidad de Granada, Granada. 
Cet, M. D. (2009): La cerámica calcolítica de Gatas en el contexto del Calcolítico del Sudeste de la Península Ibérica. Trabajo de Master de la Universitat Autonoma de Barcelona, Bellaterra, Barcelona.

Childe, V. G. (1949): L'Aube de la civilisation européenne. Payot, Paris.

Cornaggia Castiglioni, O. y Calegari, G. (1980): I pendagli ad alamaro dell'Eneolitico sardo. Atti della XXII Riunione Scientifica dell'Istituto Italiano di Preistoria e Protostoria nella Sardegna Centro-Settentrionale. Istituto Italiano di Preistoria e Protostoria, Firenze: 228-245.

Coutu, A.N., Lee-Thorp, J., Collins, M.J. y Lane, P.J. (2016): Mapping the Elephants of the 19th Century East African Ivory Trade with a Multi-Isotope Approach. PLoS ONE 11, 10): 1-23.

Delgado, S. (2013): Tecnología y distribución espacial del material macrolítico del Cerro de la Virgen de Orce (Granada). Campañas 1963-1970: una aproximación paleoecónomica. BAR International Series, 2518, Archaeopress, Oxford.

Delibes, G. (1977): El Vaso Campaniforme en la meseta norte española. Studia Archaeologica 46, Universidad de Valladolid, Valladolid.

Driesch, A. (1972): Osteoarchäologische Untersuchungen auf Iberischen Halbinsel. Studien über frühe Tierknochen von der Iberischen Halbinsel, 3, München.

Edwards, H.G.M., Nik Hassan, N. F. y Arya, N. (2006): Evaluation of Raman spectroscopy and application of chemometric methods for the differentiation of contemporary ivory specimens I: elephant and mammalian species. Journal of Raman Spectroscopy, 37: 353-360.

Espinoza, E. y Mann, J. (1992): Identification guide for ivory and ivory substitutes. World Wildlife Fund Publication. Baltimore.

Espinoza, E., y Mann, J. (1993): The History and Significance of the Schreger Pattern in Proboscidean Ivory Characterization. Journal of the American Institute for Conservation, 32, 3: 241-248.

Ferrarese Ceruti, M. L. (1974): La tomba XVI di Su Crocifissu Mannu e la cultura di Bonnanaro. Bulletino di Paletnologia Italiana, 8: 113-210.

Fonseca, R. (1988): Botones de marfil de perforación en "V" del Cerro de la Encantada (Granátula de Calatrava, Ciudad Real). Actas del I Congreso de Historia de Castilla-La Mancha 3, Toledo: 161-168.

García, L., Luciañez, M., Schuhmacher, T., Wheatley, D. y Banerjee, A. (2013): Ivory Craftsmanship, Trade and Social Significance in the Southern Iberian Copper Age: The Evidence from the PP4-Montelirio Sector of Valencina de la Concepción (Seville, Spain). European Journal of Archaeology, 16-4: 610635.

Gonçalves, V. S. (ed.) (2005): Cascais há 5000 anos. Cascáis Camara Municipal, Uniarq, Cascáis.

Guilaine, J. (1963): Boutons perforés en V du Chalcolithique pyrénéen. Bulletin de la Société préhistorique française, tome 60, 11-12: 818-827.

Harrison, R. J. (1977): The bell beakers cultures of Spain and Portugal. Peabody museum of Archaeology and Ethonology, Harvard University, Cambridge.

Hebras, C. (1965): Le Dolmen E 136 du groupe de Monpalais, commune de Taizé (Deux-Sèvres). Bulletin de la Société préhistorique française, 62-1: 139-158.

Héléna, P. (1937): Les origines de Narbonne. Privat-Didier, Toulouse-Paris.

Hopf, M. (1991a): Holzfunde vom Cerro de la Virgen, Orce (Granada). Festschrift für Wilhelm Schüle zum, 60: 173-176.

Hopf, M., (1991b): Kulturpflanzenreste aus der Sammlung Siret in Brüssel. Die Funde der Südostspaniscehn Bronzezeit aus der Sammlung Siret Ph. Von Zabern, (H. Schubart, H.Ulreic, eds.), Madrider Beitrage, 17, Zabern, Mainz: 397-413.

Javaloyas, D. (2006): Contactos culturales en el Mediterráneo a fines del II milenio A.C. Arqueoweb: Revista sobre Arqueología en Internet, 8- 1.

Kalb, Ph. (1969a): El poblado del Cerro de la Virgen de Orce (Granada)". X Congreso Nacional de Arqueología, Zaragoza: 216-225.

Kalb, Ph., (1969b): Die Siedlungarchitektur von Cerro de la Virgen bei Orce (prov. Granada). Tesis doctoral, Universidad de Freiburg, Freiburg.

Kalb, Ph. (1973): Arquitectura de las Colonias del bronce. XIII Congreso Nacional de arqueología, Zaragoza: 383-386.

Krzyszkowska, O. (1990): Ivory and related materials. An illustrated guide. Institute of Classical Studies, London.

Krzyszkowska, O. (2001): From the hippo's mouth: sources of ivory and Bronze Age trade. Bulletin of the Institute of Classical Studies, 46:219-220. 
Lafrenz, K.A. (2004): Tracing the source of the elephant and hippopotamus ivory from the 14th century B.C. Uluburun shipwreck: The archaeological, historical, and isotopic evidence. Graduate Theses and Dissertations. University of South Florida, Tampa.

Lizcano, R., Nocete, F. Y Peramo, A (2009): Las Eras: Proyecto de Puesta en Valor y Uso Social del Patrimonio Arqueológico de Úbeda (Jaén). Editorial, Huelva.

Locke, M. (2008): Structure of Ivory. Journal of Morphology, 269: 423-450.

López, J. A. (2006): Consideraciones en torno al Horizonte Campaniforme de Transición. Archivo de prehistoria levantina, 26: 193-244.

López, J.A. (2011): Asta, hueso y marfil. Artefactos óseos de la Edad del Bronce en el Levante y Sureste de la península Ibérica (c. 2500-c. 1300 cal BC). Serie Mayor 9, MARQ, Museo Arqueológico Provincial, Alicante.

Mérida, V. (1997): Manufacturing proces of V-perforated ivory buttons. Preceedings of the 1993 Bone Modification Conference, Hot Springs, South Dakota (L. Hannus, L. Rossum, R. Winham, eds.), Occasional Publication 1, Archeology Laboratory, Augustana College, Sioux Falls: 1-11.

Molina, F., Cámara, J. A., Afonso, J. A. y Nájera, T. (2014): Las sepulturas del Cerro de la Virgen (Orce, Granada). Diferencias cronológicas y diferencias sociales. Revista Atlántica-Mediterránea de Prehistoria y Arqueología Social, 16: 121-142.

Molina, F., Cámara, J.A., Dorado, A. y Villarroya, M. (2017): El fenómeno campaniforme en el Sudeste de la Península Ibérica: el caso del Cerro de la Virgen (Orce, Granada). Sinos e taças. Junto ao Oceano e mais longe. Aspectos da presença campaniforme na Península Ibérica (V.S. Gonçalves y A.C. Sousa, eds.), Lisboa: 112-129.

Molina, F., Cámara, J.A., Capel, J., Nájera, T. y Sáez, L. (2004): Los Millares y la periodización de la Prehistoria Reciente del Sudeste. Simposios de Prehistoria Cueva de Nerja. II. La problemática del Neolítico en Andalucía. III.Las primeras sociedades metalúrgicas en Andalucía. Fundación Cueva de Nerja, Nerja: 142-158.

Montero, I. (1994): El origen de la metalurgia en el sudeste de la Península Ibérica. Instituto de Estudios Almerienses, Almería.

Morillo, J. M., Pau, C. y Guilaine, J. (en prensa): The proboscidean ivory adornments from the Hypogem of Padru Jossu (Sanluri, Sardinia, Italy) and the Mediterranean Bell Beaker. Zephyrus, LXXXII.

Murillo, M. (2013): Producción y consumo de plata. Un análisis comparativo entre la sociedad argárica y los primeros asentamientos orientalizantes en el Sur de la Península Ibérica. Tesis doctoral, Universidad de Granada, Granada.

Nocete, F., Vargas, J. M., Schuhmacher, T. X., Banerjee, A. y Dindorf, W. (2013): The ivory workshop of Valencina de la Concepción (Seville, Spain) and the identification of ivory from Asian elephant on the Iberian Peninsula in the first half of the 3rd millennium BC. Journal of Archaeological Science, 40-3: 1579-1592.

Ontañón, R. (2002): Un "botón" prismático con doble perforación en V inédito procedente del dolmen de Pagobakoitza, en el contexto de los elementos de adorno del Calcolítico Cantábrico. Munibe (Antropologia-Arkeologia), 54: 103-115.

Palombo, M. R. y Villa, P. (2001): Schreger lines as support in the Elephantinae identification. The World of Elephants (G. Cavarretta, P. Gioia, V. Mussi, M.R. Palombo, eds.), Consiglio Nazionale delle Ricerche: 656-660

Pascual, J. L. (1998): Utillaje óseo, adornos e ídolos neolíticos valencianos. Serie de Trabajos Varios del Servicio de Investigación Prehistórica del Museo de Prehistoria de Valencia, 95, Valencia.

Pau, C. (2012): Los botones campaniformes sardos y sus analogías con los adornos de la Península Ibérica y de otras zonas del Mediterráneo. Saguntum, 44: 67-76.

Pau, C. (2015): Los objetos de adorno personales campaniformes de los yacimientos granadinos: el caso del Cerro de la Virgen, Orce, Granada. Revista Atlántica Mediterránea de Prehistoria y Arqueología Social, 17: 263-271.

Pau C. (2016): Los objetos de adorno en el Mediterráneo occidental en época Campaniforme y su trascendencia social. Tesis doctoral, Universidad de Granada, Granada.

Pau C. y Molina F. (2015): Los botones con perforación en V del poblado de los Castillejos de Montefrío. Bollettino di Archeologia, VI, 1: 89-110 
Pérez, C. L. y López De Calle, C. (1986): Relaciones culturales en el Eneolítico del Valle del Ebro a partir de un análisis especifico sobre elementos de adorno en yacimientos riojanos. Segundo Coloquio sobre historia de la Rioja 1, Universidad de La Rioja, Colegio Universitario de la Rioja, Logroño: 19-36

Peyronel, L. (2016): Bone and ivory manufacturing at Ebla (Syria) during the Early and Middle Bronze Age (c. 2500-1600 BC). Levant. The Journal of the Council for British Research in the Levant, 48- 2: 184-196.

Roche, J. y Da Veiga Ferreira, O. (1961): Revision des boutons perforés en V de l'énéolithique portugais. L'Anthropologie, 1-2: 67-73.

Rodanés, J. M. (1987): La industria ósea prehistórica en el Valle del Ebro (Neolítico- Edad del Bronce). Diputación general de Aragón, Zaragoza.

Rodríguez-Ariza, Ma O. y Esquivel, J. A., (2005): Una valoración de la paleovegetación del sureste del la Península Ibérica durante la prehistoria reciente a partir de aplicaciones estadísticas en antracología". VI Congreso Ibérico de Arqueometría, Avances en Arqueometría, Girona: 263-272.

Rovira, S., Montero, I. y Consuegra, S. (1997): Cerro de la Virgen. Las primeras etapas metalúrgicas en la Peninsula Iberica I: Analisis de materiales (S. Rovira, I. Montero y S. Consuegra, eds.), Instituto Universitario Ortega y Gasset, Madrid: 206-208.

Sáez, L. y Schüle, W. (1987): Informe preliminar sobre los trabajos y estudio del material del Cerro de la Virgen Orce (Granada). Anuario Arqueológico de Andalucía 1985, II: 263-265.

Schüle, W. (1966): El poblado del Bronce Antiguo en el Cerro de la Virgen de Orce (Granada) y su acequia de regadío. IX Congreso Nacional de Arqueología, Zaragoza: 113-121.

Schüle, W. (1967): Feldbewässerung in Alt-Europa. Madrider Mitteilungen, 8: 79-99.

Schüle, W. (1976): Die frühmittelalterliche Siedlung auf dem Cerro de la Virgen in Orce (Granada). Glockenbecher symposium, Bussum: 419-421.

Schüle, W. (1980): Orce und Galera: zwei Siedlungen aus dem 3 bis 1 Jahrtausend v. Chr. Im Südosten der Iberischen Halbinsel I: übersicht über die Ausgrabungen 1962-1970. Phillip von Zabern, Mainz am Rhein.

Schüle, W. (1986): El Cerro de la Virgen de la Cabeza, Orce (Granada). Consideraciones sobre su marco ecológico y cultural. Homenaje a Luis Siret (1934- 1984), Junta de Andalucia, Sevilla: 208-220.

Schüle, W., Pellicer, M. (1964): Excavaciones en la zona de Galera (Granada). VIII Congreso Nacional de Arqueología, Zaragoza: 387-392.

Schüle, W., Pellicer, M. (1966): El cerro de la Virgen, Orce (Granada) I. Excavaciones Arqueológicas en España, 46, Ministerio de Educación Nacional, Madrid.

Schuhmacher, T. X. (2011): Elfenbein des Chalkolithikums und der Frühen Bronzezeit auf der iberischen Halbinsel: Ergebnisse einer interdisziplinären Forschungsprojekts. Elfenbein und Archäologie, INCETIUS Tagungsbeiträge 2004-2007, (A. Banerjee, C. Eckmann, eds.), RGZM 7, Mainz: 91-122.

Schuhmacher, T. (2012): El marfil en España desde el Calcolítico al Bronce Antiguo. Elfenbeinstudien. Faszikel 1: Marfil y elefantes en la Península Ibérica y el Mediterráneo occidental. Actas del coloquio internacional en Alicante el 26 y 27 de noviembre 2008 (A. Banerjee, J.A. López Padilla y T.X. Schumacher, Eds.). Iberia Archaeologica, 16:1. Deutsches Archäologisches Institut/Diputación de alicante/ MARQ. Museo Arqueológico de Alicante, Verlag Philipp von Zabern, Mainz: 45-68.

Schumacher, T., Banerjee, A. (2012): Procedencia e intercambio de marfil en el Calcolítico de la Península Ibérica. Revista del Museu de Gavà, 5: 289-298.

Schuhmacher, T., Banerjee, A., Dindorf, W., Sastri, Ch. y Sauvage, Th. (2013): The use of Sperm whale ivory in Chalcolithic Portugal. Trabajos de Prehistoria, 70: 185-203.

Schuhmacher, T. X., Cardoso, J. L. y Banerjee, A. (2009): Sourcing african ivory in Chalcolithic Portugal. Antiquity, 83-322: 983-997.

Taramelli, A. (1909): Nuovi scavi nella necropoli preistorica di Anghelu Ruyu. Monumenti Antichi dei Lincei XIX: 397-540.

Trapani, J., Fisher, D.C. (2003): Discriminating Proboscidean Taxa Using Features of the Schreger Pattern in Tusk Dentin. Journal of Archaeological Science, 30, 4: 429-438.

Uerpmann, H. P. (1990): Domestication des Pferdes im Chalkolithikum West-und Mitteleuropas. Madrider Mitteilungem, 31: 109-153.

Ulreich, H. (1980): Unteruchungen der Keramik des Cerro de la Virgen, Orce (Granada). Tesis doctoral, Universität Freiburg, Freiburg. 
Ulreich, H. (1981): Unterscheidung und statistiche Untersuchung der Keramikklassen des Cerro de la Virgen, Orce (Granada). Madrider Mitteilungen, 22: 89-126.

Ulreich, H. (1988): Bemerkungen zu kupferzeitlichen Knochenspitzen vom Cerro de la Virgen, Orce (Granada). Madrider Mitteilungen, 22: 89-126.

Ulreich, H. (1995): Observaciones sobre las puntas de hueso ene el edificio IB1-6 del Cerro de la Virgen, Orce, Granada, Origens estruturas e relaçows das culturas calcoliticas da Peninsula Iberica, Actas das I Jornadas Arqueologicas de Torres Vedras (M. Kunst. coord.), Trabalhos de Arqueologia, 7. Lisboa: 263-272.

Uscatescu, A. (1992): Los botones de perforación en " $V$ " en la Península Ibérica y las Baleares durante la Edad de los metales. Ed. Foro Arqueología, Proyectos y publicaciones, Madrid.

Usai, A. (1992-93): Considerazioni sulle relazioni tra la Sardegna e L'Egeo durante il Neolitico e il Calcolitico. Studi Sardi XXX: 329-439.

Valera, A. C., Schuhmacher, T. X. y Banerjee, A. (2015): Ivory in the Chalcolithic enclosure of Perdigões (South Portugal): the social role of an exotic raw material. World Archaeology, 47-3: 390-413.

Virag, A. (2012): Histogenesis of the Unique Morphology of Proboscidean Ivory. Journal of Morphology, 273, 12: 1406-1423.

Yener, K.A. (2007): The Anatolian Middle Bronze Age kingdoms and Alalakh: Mukish, Kanesh and trade. Anatolian Studies, 57: 151-160. 